\title{
Best Practices for Dealing with Price Volatility in Utah's Residential Construction Market
}

James Packer Smith

Brigham Young University - Provo

Follow this and additional works at: https://scholarsarchive.byu.edu/etd

Part of the Construction Engineering and Management Commons

\section{BYU ScholarsArchive Citation}

Smith, James Packer, "Best Practices for Dealing with Price Volatility in Utah's Residential Construction Market" (2010). Theses and Dissertations. 2260.

https://scholarsarchive.byu.edu/etd/2260

This Thesis is brought to you for free and open access by BYU ScholarsArchive. It has been accepted for inclusion in Theses and Dissertations by an authorized administrator of BYU ScholarsArchive. For more information, please contact scholarsarchive@byu.edu, ellen_amatangelo@byu.edu. 
Best Practices for Dealing with Price

Volatility in Utah’s Residential

Construction Market

James Smith

A thesis submitted to the faculty of

Brigham Young University

in partial fulfillment of the requirements for the degree of

Master of Science

Kevin R. Miller, Chair

Jay P. Christofferson

D. Mark Hutchings

School of Technology

Brigham Young University

August 2010 



\author{
ABSTRACT \\ Best Practices for Dealing with Price \\ Volatility in Utah's Residential \\ Construction Market
}

James Smith

School of Technology

Master of Science

Price volatility is a consistent problem that affects all of the parties involved in the residential construction industry. The myriad factors that can have an impact on construction costs are such that it is extremely hard to anticipate upcoming changes in a timely and accurate way. When prices fluctuate during the course of a project, estimates become erroneous and completion of projects within expected budgets becomes difficult. Increasing prices typically leave contractors with the majority of the risk burden due to the enforceability of contracts that are likely to have been executed months prior. The risk associated with the owner's role primarily exists when prices decrease and they are required to make payments on pre-existing contracts that do not accurately reflect "actual" costs at the time of construction. The risk of price volatility needs to be managed.

Numerous methods have been developed for managing the risk of price volatility. The various methods available are implemented based on the parties involved, the types of contracts being used, and the existing market conditions. Typical practices transfer the risk of price volatility to other involved parties, be it the owner, the contractor, subcontractors, or suppliers. However, no method has proven completely effective at removing the risks associated with price volatility. Involved parties need to utilize a combination of best practices to protect themselves. They need to coordinate and communicate with the other parties to ensure that the risk of price volatility is appropriately accounted for and managed throughout the construction process.

Keywords: James Smith, price, volatility, fluctuation, residential construction 



\section{ACKNOWLEDGMENTS}

Upon the much anticipated completion of this research project, I wish to express my gratitude and sincere appreciation to those who are most rightfully ready for it to be done. First and foremost, thank you to my one and only, Kim, and to my three beautiful children, Natalie, Kaylee, and Packer. Their support and encouragement have been, and will continue to be invaluable in all of my life's endeavors. Additionally, thank you to my graduate committee for their guidance and time, and to the panel members for their insight and commitment to the research project. 

LIST OF TABLES .......................................................................................................

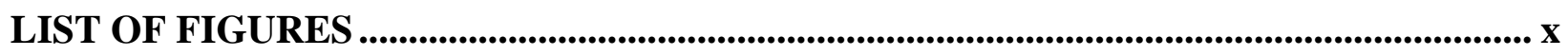

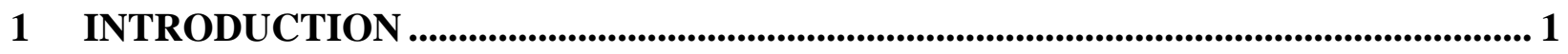

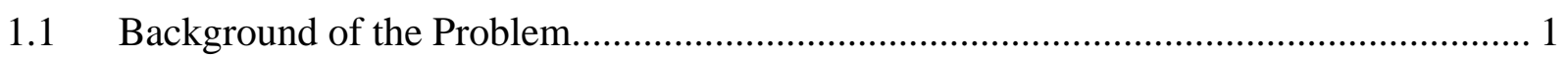

$1.2 \quad$ Statement of the Problem ...................................................................................... 2

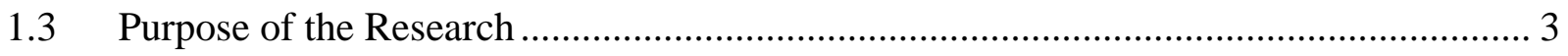

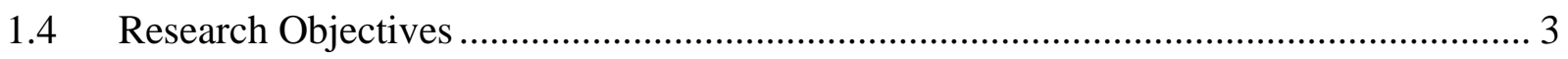

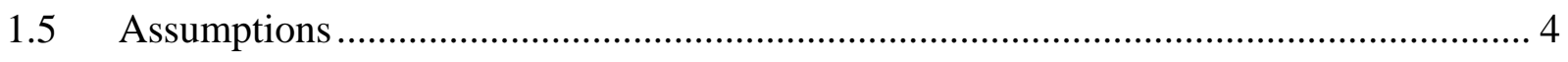

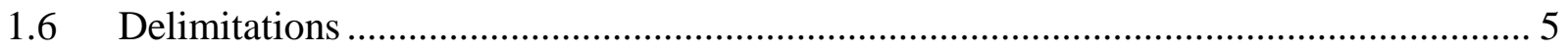

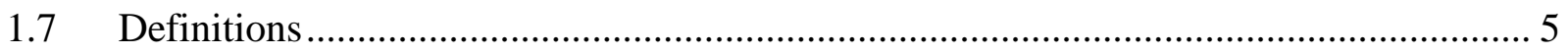

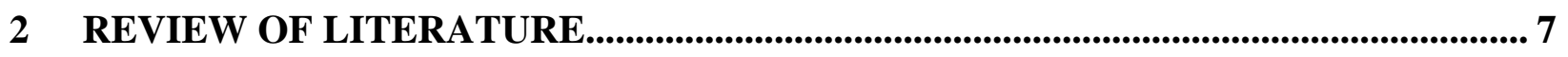

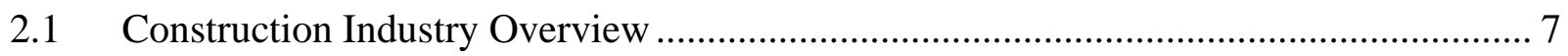

2.2 Primary Causes of High Construction Costs............................................................. 8

2.3 Examples of the Effect of Price Fluctuation .................................................................. 9

2.4 Construction Industry Players ……………………................................................ 11

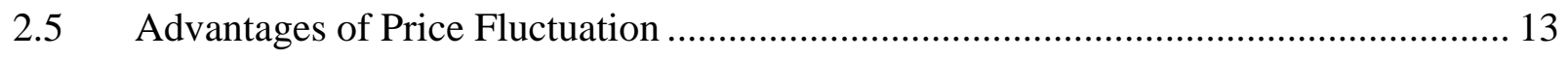

2.6 Construction Contract Ramifications .................................................................... 14

2.6.1 Types of Construction Contracts .................................................................... 14 
2.6.2 Related Contractual Language .............................................................................. 16

2.7 Risks Inherent to Contracting................................................................................... 17

2.8 Risks Associated with Price Fluctuation.................................................................. 19

2.9 Current Practices for Dealing with the Risk Associated with Price Fluctuation ............ 21

2.10 Price Adjustment Clauses...................................................................................... 25

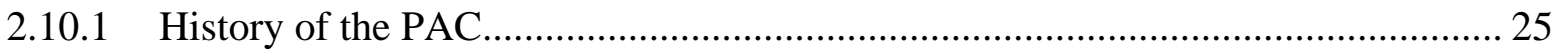

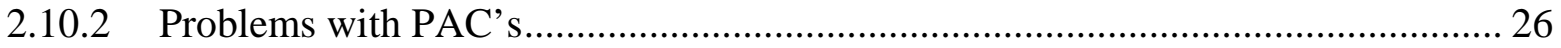

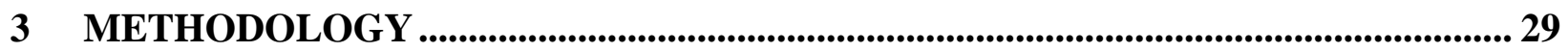

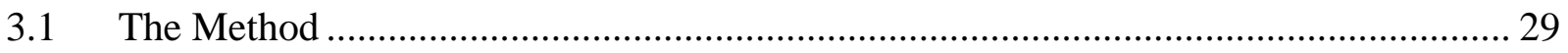

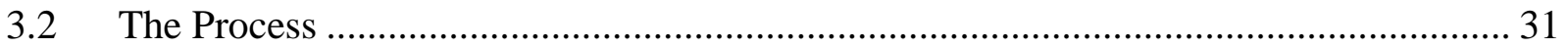

3.2.1 Step One - Selection of the Panel Members.............................................................. 31

3.2.2 Step Two - Development of the Round 1 Questionnaire ......................................... 32

3.2.3 Step Three - Testing the Questionnaire................................................................. 33

3.2.4 Step Four - Transmission of the Round 1 Questionnaire ......................................... 33

3.2.5 Step Five - Analysis of the Round 1 Responses...................................................... 34

3.2.6 Step Six - Preparation of the Round 2 Questionnaire ............................................. 34

3.2.7 Step Seven - Administration of the Round 2 Questionnaire ................................... 34

3.2.8 Step Eight - Data Analysis ..................................................................................... 34

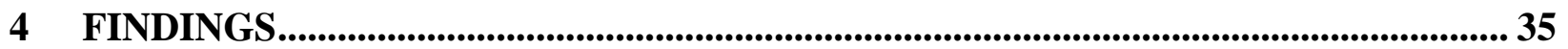

4.1 Panel Member Company Background …………............................................................ 36 
4.2 Current Contracting Methods.

4.3 Current Practices for Dealing with Price Fluctuation ............................................... 45

4.4 Risk Allocation of the Various Contracting Methods ............................................... 58

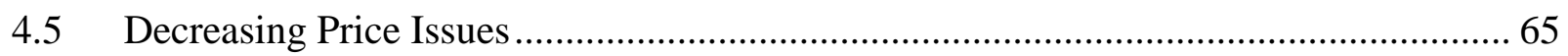

5 CONCLUSIONS AND RECOMMENDATIONS ................................................ 69

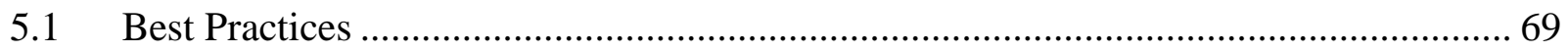

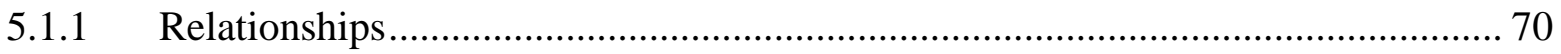

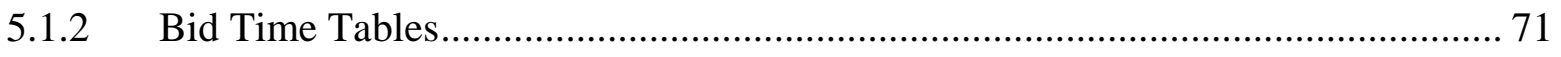

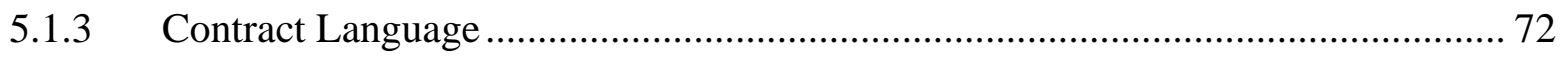

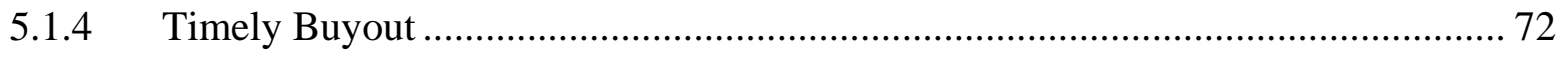

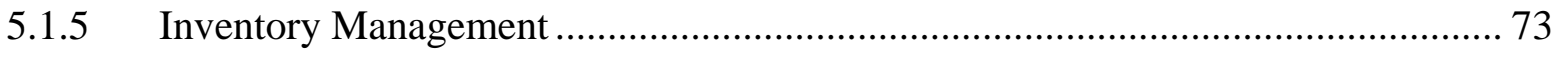

5.2 Recommendations for the Industry …............................................................ 74

5.3 Recommendations for Additional Study ....................................................... 75

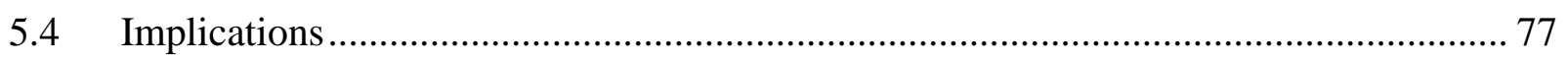

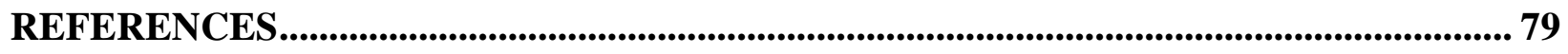

APPENDIX A. SELECTED PANEL MEMBERS........................................................ 83

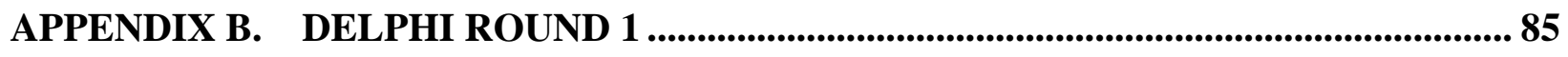

APPENDIX C. DELPHI ROUND 2 ........................................................................................ 89 


\section{LIST OF TABLES}

Table 2-1: Construction material \% price change from 2006 to 2007

Table 2-2: Most important inflationary and deflationary factors

for pricing time-related risks by general contractors

Table 2-3: Results on issues in contract price escalation.

Table 4-1: General contractor respondents’ company information

Table 4-2: Subcontractor respondents’ company information.

Table 4-3: Supplier respondents’ company information

Table 4-4: Average use of contracting methods for general contractors surveyed.

Table 4-5: Average \% increase added to materials and labor to cover potential price fluctuation

Table 4-6: Average \% increase added to equipment, sub-contractors, and other items to cover potential price fluctuation.

Table 4-7: Average use of contracting methods for sub-contractors surveyed

Table 4-8: Average use of contracting methods for suppliers surveyed

Table 4-9: Total number of responses per price fluctuation management method.

Table 4-10: General contractors’ responses per price fluctuation method 50

Table 4-11: Sub-contractor responses per price fluctuation method 53

Table 4-12: Supplier responses per price fluctuation method 56 
Table 4-13: Average overall equitability rankings by contracting method

Table 4-14: General contractors' average current and desired risk

allocation to each party for each type of contracting method....

Table 4-15: General contractor panel member’s average equitability rankings by contracting method....

Table 4-16: Sub-contractors' average current and desired risk allocation to each party for each type of contracting method.

Table 4-17: Sub-contractor panel members’ average equitability rankings by contracting method.

Table 4-18: Suppliers' average current and desired risk allocation to each party for each type of contracting method. 64

Table 4-19: Supplier panel members’ average equitability rankings by contracting method. 


\section{LIST OF FIGURES}

Figure 2-1: Schematic Depiction of the Supply Chain in Residential Construction ................... 12 


\section{INTRODUCTION}

\subsection{Background of the Problem}

Within common residential construction practices there are a variety of methods available for dealing with the inevitable price fluctuation that occurs with labor and material costs during the course of a given project. Often this fluctuation is inconsequential enough that minor adjustments can be absorbed without major impact on the involved parties. However, periodically, the industry experiences fluctuation, either in a positive or negative direction, that can have a drastic impact on the companies and/or individuals associated with the transaction.

In recent years there has been a dramatic increase in the dissolution of construction companies, along with an increase in the number of bankruptcy claims made by owners. Deseret

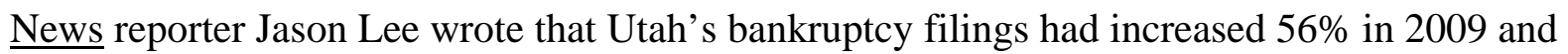
referenced the Associated Press statement that nationally, 2009 was the seventh worst year on record for bankruptcy filings. With communication, material transportation, and the global market developing like they have, the effect of a cement shortage, or an increase in demand for copper on the other side of the world has the potential to have an impact on individual markets like Utah’s.

The methods that have been developed for dealing with this recurring problem differ based on the parties involved, the types of contracts being used, and the existing market conditions. Typical practices transfer the risk of price volatility to other involved parties, be it the owner, the contractor, subcontractors, or suppliers. When prices increase, contractors end up 
with the majority of the risk burden due to the enforceability of contracts that were likely

executed months, if not years, prior to the price increase. Likewise, subcontractors and suppliers can get trapped in the same scenario. The risk associated with the owner's role primarily exists when pricing drops and they are required to make payments on pre-existing contracts that do not accurately reflect "actual” costs at the time of construction.

There are a variety of alternatives beyond contract language for managing the risk of price fluctuation, but they typically necessitate additional costs for storage of pre-purchased materials or financing of up-front costs spent to secure pricing at the time of the bid. Therefore, someone ends up accepting the risk of price volatility and is required to take measured to protect against it. So the problem exists: what is the best way to deal with these price fluctuations so that no individual party takes an inordinate amount of risk in the construction process?

\subsection{Statement of the Problem}

The problem existing in Utah's residential construction industry, as it pertains to this paper, is that price fluctuation exists and affects each of the parties involved in the process. The existence of price fluctuation poses a potentially significant risk to the contracting parties. The building industry is inherently risky by nature. Therefore, one of the goals of contracting parties is to minimize the risks they are exposed to through focused management of the contributing factors. However, despite the extreme difficulty of accurately predicting future price fluctuations due to myriad factors, globally and locally, contracting parties should be able to anticipate the distinct possibility that they may occur, and thus have in place a mutually agreeable system for dealing with them. This problem falls into two general categories. The first is contractual language or other agreements that are used to place liability on only one of the involved parties. 
This often results in an unfair burden on that party directly resulting from forces which are outside their ability to control. The second is perhaps more common than the first, and it is the complete lack of a plan or contractual language anticipating price fluctuations. In this scenario, the result is often costly litigation. When litigation occurs, additional, sometimes unbearable, financial burdens on one or more of the parties involved, not to mention the unnecessary stress and time commitment required to resolve the problem. In essence, it is often unclear how to best plan and prepare for substantial price fluctuations in order to protect the individual companies involved in the transaction.

Question: What methods are being used to minimize the risks associated with price fluctuations on materials and labor for the parties involved in the residential construction contract? How effective do the involved parties find these available options?

\subsection{Purpose of the Research}

The purpose of this research is to identify the methods for managing price volatility that are currently being utilized by each of the parties involved in the construction process. The results of this work will yield recommendations for dealing with this problem in Utah's residential construction market.

\section{$1.4 \quad$ Research Objectives}

The objectives of this research are to identify the following:

1. Factors that have an impact on building material, labor, and/or equipment price fluctuation. 
2. Methods that exist, and are currently being practiced to deal with this problem by each of the following parties within Utah’s residential construction industry :
a. General Contractor
b. Subcontractor
c. Supplier

3. The ability of the various practiced methods to minimize risk for each party.

4. The best methods for dealing with the problem of price fluctuation.

The research was conducted using the Delphi method. This method consists of a series of questionnaires given to a qualified panel of industry experts, resulting in valid, accurate information regarding current practices (Helmer and Rescher, 1959). The application of this method provides the most current data available regarding existing practices and their effectiveness. It also provides insight into any new trends or practices that parties are implementing to deal with this expanding problem.

\subsection{Assumptions}

- A problem associated with price fluctuation exists in the construction industry that doesn't have an equitable solution and therefore often results in inequitable burdens on one or more parties in the transaction.

- The financial burdens carried by parties in these types of transactions are substantial enough to warrant research and resolution. 


\subsection{Delimitations}

- This research focuses only on residential construction and does not necessarily apply to commercial, or industrial construction.

- The Delphi method is limited to interviewing professionals in Utah's construction industry.

\subsection{Definitions}

General Contractor: The person or entity holding the prime contract in a construction project. Typically viewed as the responsible party for all facets of the actual construction process. Contractors involved in this research are legally licensed and insured.

Subcontractor: Contractors other than the primary contractor (secondary, tertiary, etc) who perform some part of the general contractor's obligation. This entity typically enters into a contract with the general contractor.

Owner: The architect's or engineer's client; the owner of a project such as a government agency; the person, firm, or corporation with which a contract has been made for the payment of the work performed under that contract.

Owner's Representative: A person employed by the owner to inspect construction and ensure compliance with the contract on the owner's behalf.

Supplier: A person or organization who supplies materials or equipment for the work, including items fabricated to a special design but who does not perform labor at the site. Contract Administration: The management of all actions, on behalf of the owner, to assure compliance with the contract and construction documents. 
Contract: The written agreement executed between an owner, a department or agency and the contractor, covering the performance of the work and the furnishing of labor and materials. The contract binds the contractor to perform the work and furnish the labor and materials, and the owner, department or agency is obligated to compensate him at the mutually established and accepted rate or price. Different types of contracts exist and will be reviewed in Chapter 2 of this paper. (a.k.a. agreement)

Date of Agreement: The date stated on the face of the agreement. If no date is stated, it could be the date on which the agreement is actually signed, if this is recorded, or it may be the date established by the award. (Rohan, 1996) 


\section{REVIEW OF LITERATURE}

\subsection{Construction Industry Overview}

Construction is a dynamic and extremely competitive multi-billion dollar industry in the United States today. High risk-high reward scenarios are commonplace and therefore one of the primary goals of the construction company is to manage, and/or transfer that risk. Perhaps more so than many industries, the risks associated with construction contracting can come from any one of an assortment of factors that have the ability to greatly impact the project in a positive or negative manner. These sources of risk include both internal and external factors. Some of the factors to consider include, but are not limited to, the following:

1. Weather - hurricanes, tsunamis, earthquakes, etc.

2. Material/Labor price fluctuation

a. Typically caused or accentuated by a shortage or abundance of either material or labor in our supply and demand marketplace.

3. Marketplace financing

4. Underground conditions

5. Global market conditions - China's concrete supply/demand, etc.

6. Transportation

7. Communications

8. Government policies (interest rates), taxes, inflation, and tariffs

9. Internal management policies and skill levels 
Throughout history, in a "competitive bid” or Capitalistic economic system, there has inevitably been some level of risk accepted on the contractor's part. That risk has manifested itself in different ways. "In ancient Babylon, where construction contracts were awarded as design/build contracts, the law of the land specified that if the dwelling or any part thereof failed and injured a member of the owner's family, a like member of the builder's family would be injured in the same manner” (Murray, 1993). Thankfully, this consequence has not endured to our modern day industry. However, the risk associated with contracting is still in full effect.

Within common construction practices, there are a variety of methods available for dealing with, and ideally mitigating, the associated risks. By so doing, the contractor can avoid excessive costs being incurred on projects that have strict estimates which must be met in order to consider the project successful.

\subsection{Primary Causes of High Construction Costs}

Chuck Dahill, CEO of PinnacleOne, performed a survey in which 57\% of the public owners' who responded claimed their primary concern with project delivery was to control costs (Tulacz, 2006). In an investigation into the competitive bid construction industry of Nigeria, a survey completed by industry professionals found that delays and direct cost overruns were the principal factors leading to high costs. This information was used to create a second survey designed to discover what factors most heavily impacted the delays and cost overruns that led to higher costs. Results from this survey indicated that high costs can be minimized by focusing attention on the following items:

1. Minimizing lapses in the management of human and material resources.

2. Managing material shortages. 
3. Improving methods of financing and payments for completed works.

4. Improved contract management.

5. Management of price fluctuation

a. Identified as the most important factor responsible for the escalation of the project costs (Okpala, 1988).

This research focuses on the "management of price fluctuation" item from the above list. Price fluctuation in required resources over project duration is widely accepted as one of the primary causes of inaccuracy of cost estimating, resulting in higher costs of construction ( $\mathrm{Yu}$, 2005). Approximately one in three estimates are at a variance from the actual total net cost by more than $6 \%$. Additionally, the likelihood of the estimated cost being in error by more than $40 \%$ on a given line item is one in three (Barnes, 1971).

\subsection{Examples of the Effect of Price Fluctuation}

Price fluctuation occurs on both the labor and materials sides of a project. However, typically, materials account for 40-45\% of the total cost of all construction work (Agapiou, 1998) and therein lies the greatest risk for skyrocketing, or conversely, plummeting prices. A recent example of this situation was recorded in an interview by Lisa Bisbee in July of 2008. Camplex’s Wyoming Center General Manager, Dan Barks, said that in the course of 10 days, copper prices drove the cost of materials to build the Center up by more than $\$ 1$ million dollars. Additional stress was added to the situation as devastating hurricanes fueled dramatic increases in the cost of oil and steel products shortly thereafter. Overall, the cost to build the multi-event center increased by $\$ 16$ million over the original estimate due to these unforeseen price fluctuations (Bisbee, 2008). 
In residential construction, another poignant example of this problem occurred in the Phoenix market in 2001 with regards to the residential lumber supply chain. Lumber prices increased almost $60 \%$ in the course of only a few months in response to uncertainty about US government tariff policies relating to Canadian forest products. At the time, typical high-volume home builders had an average construction cycle time between 6-8 months and operated on fixed price contracts with owners, usually agreed to at the beginning of the construction process (Bashford, 2003). With prices increasing drastically during this course of construction, it is obvious that price fluctuation management can become critical to a company's survivability in a variety of circumstances.

On the other side of this issue is the difficulty faced during times of cost decrease as was evidenced in 2009. In a scenario like that which took place in New York City, where construction costs had fallen for three consecutive quarters, prices dramatically decreased after contracting a project (Fung, 2009). In certain types of contracts under these circumstances, builders could hold owner's to previously agreed upon prices despite the fact that they no longer accurately reflect the going market rates. The renegotiation of these existing contracts becomes a major concern for the contractors and subcontractors being forced to reduce pricing (Setzer, 2009). The inequality created when prices fluctuate up or down, has the potential to affect all parties involved in the transaction.

Table 2-1 shows the percentage change in price experienced by various construction materials between 2006 and 2007. 
Table 2-1: Construction material \% price change from 2006 to 2007

\begin{tabular}{|l|ccccccc|}
\hline Material & July '06 & August '06 & September '06 & October '06 & November '06 & December '06 & January '07 \\
\hline \hline Aluminum Sheet & +17.9 & +16.2 & +15.2 & +14.8 & +15.6 & +14.2 & NA \\
Asphalt Mixture & +35.3 & +36.7 & +33.6 & +30.2 & +27.9 & +27.0 & NA \\
Cement & +11.4 & +11.6 & +11.5 & +11.5 & +11.2 & +10.7 & +7.5 \\
Copper, pipe and tube & +123.7 & +103.0 & +84.8 & +65.2 & +48.4 & +34.8 & +26.7 \\
Diesel Fuel & +25.1 & +24.7 & -5.3 & +25.2 & -4.3 & +2.3 & -8.2 \\
Gypsum Products & +25.8 & +19.9 & +16.6 & +14.3 & +10.1 & +5.0 & +2.8 \\
Lumber, softwood & -7.5 & -8.5 & -11.0 & -16.0 & -14.5 & -16.1 & -15.5 \\
PVC Products & +18.3 & +18.9 & +17.9 & +9.8 & +0.6 & -0.6 & -3.4 \\
Ready-Mix Concrete & +11.7 & +11.2 & +10.5 & +10.5 & +9.7 & +9.8 & NA \\
Wire and Cable & +45.4 & +48.1 & +42.6 & +39.9 & +31.1 & +22.6 & +16.6 \\
\hline
\end{tabular}

(Adapted from Ichniowski, 2007)

Understanding that there is a precedent set for prices to increase on a scale as extreme as that shown in the Table 2-1, lends weight to the idea that managing this potential price fluctuation is a critical component to the success and longevity of all construction companies.

\subsection{Construction Industry Players}

There are a number of parties involved in the construction process. This paper focuses on those primarily impacted by material and/or labor price fluctuation. This group can be identified as the Supply Chain for any given project. The supply chain generally does not include the architect, draftsmen, or the engineer despite their vital roles in successful project completion. Figure 2.1 depicts the typical supply chain for a residential project. This general practice of a supplier providing materials to a yard or warehouse, who provides material to the trade contractor, who then passes completed services on to the General Contractor, who finally passes the completed project onto the owner, is basically repeated by every necessary trade in the process. 


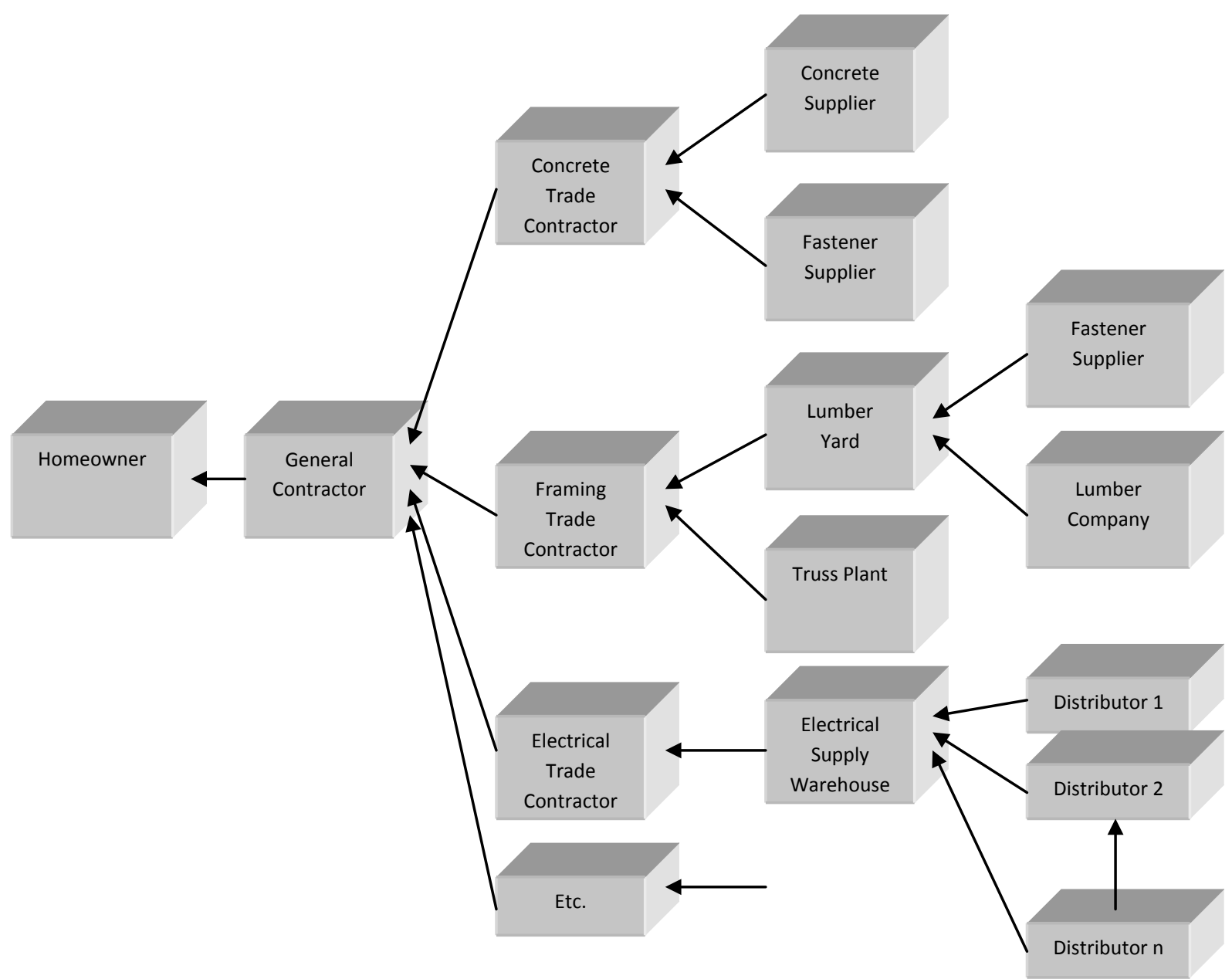

Figure 2-1: Schematic Depiction of the Supply Chain in Residential Construction (Adapted from Walsh, 2003)

Each of the players in this residential supply chain can be categorized into one of four groups that will be reviewed in this paper. The four categories are as follows:

1. Owner - inclusive of owner's representative, homebuyers, investors, and any other end users.

2. General Contractor - inclusive of construction managers or other party's responsible for the overall project. Typically contracts with both the Owner and the Subcontractors.

3. Sub-contractor - trade specific contractors hired to complete portions of the overall project. Typically contracts with the General Contractor and the Supplier. 
4. Supplier - anyone that provides materials necessary for completion of the SubContractor's or General Contractor's scope of work. Contracts with Subcontractors and potentially other suppliers/warehouses/yards.

Each of these parties is exposed to the risks associated with price fluctuation. When prices increase during the course of a project, subcontractors and suppliers are typically forced to maintain contract pricing despite their increased costs. When pricing is increasing in the market place in general, subcontractors and suppliers may find it difficult to pass along those higher prices and still be competitive enough to win work. Leon Levy, Chairman of Urban

Substructures Co. Inc., New York City said, "Concrete subs have had to learn to live with razorthin margins and hard-nosed owners". These same subs are being forced to absorb inflationary costs as owners refuse to accept the typical 3 to 5\% increase (Grogan, 1993).

\subsection{Advantages of Price Fluctuation}

Thus far in this paper, price fluctuation has been assigned a rather negative connotation. However, some research from the literature review suggests otherwise. More than a half a century ago, Waugh asked the question of whether or not the general market consumer can benefit from price instability (Waugh, 1944). In more recent research on the topic, Akio Matsumoto demonstrated analytically as well as numerically the following two pertinent results:

1. Chaotic price dynamics can be beneficial for one consumer and harmful to the other consumer.

2. The whole economy is possibly better off with chaotic fluctuations than at a stationary state in the long-run (Matsumoto, 2003). 
Although these results are not specifically detailing the construction industry, they imply that as a general rule in the economy as a whole, chaotic price fluctuations can be preferable to a stationary state. Additionally, Result 1 listed above gives further weight to the overall goal of this research, which is to determine what method for dealing with price fluctuation provides the most equitable solution between the various parties or consumers.

\subsection{Construction Contract Ramifications}

\subsubsection{Types of Construction Contracts}

The type of contract that is entered into between the respective parties plays a major role in the transfer and/or acceptance of the risk of price fluctuation. There may be multiple types of contracts entered into on any given project. The general contractor may enter into a different type of contract with the owner than with the subcontractors. Unfortunately, too often in the

residential construction industry, contracts fail to assign responsibility or to specify methods for dealing with the changes in price that can occur after the contract has been signed. The following list includes the major types of contracts that are currently in use in residential construction, along with each type of contract's implications on the issue of price volatility.

1. Fixed Price Contract - Also called a "Lump Sum Contract," this type of contract has typically been the owner's contract of choice because it minimizes uncertainty and gives them, in theory, a firm number to rely on throughout the construction process. As most projects require financing, having a fixed contract price and budget assists in the loan approval and implementation of the lending process. However, parties involved in fixed price contracts should be aware of the risks that are also associated with this contract. Especially as it pertains to price fluctuation. Courts do not 
typically offer relief for price increases that occur when parties are locked into a fixed price contract.

2. Cost Plus Contract - In this type of contract, the owner agrees to pay the contractor a percentage of the actual cost of construction, in addition to the actual cost. These types of contracts are common when the nature of the project is such that it is very difficult to obtain accurate estimates. On custom projects where there is no precedent set to verify actual costs, this can be an ideal form of contracting. Also, when the work to be done is not fixed at the time the contract is entered into, this type of contract allows for flexibility throughout the process. There are also disadvantages to this type of contract. There is little to no incentive to the contractor to value engineer the project, eliminate waste, or manage bidding to minimize cost. In fact, it encourages just the opposite since the greater the cost, the greater the contractor's resulting income. Under a cost plus contract, the owner essentially accepts the risk for market price fluctuations, whether positive or negative, as those costs are simply passed directly on to them throughout the process.

3. Guaranteed Maximum Price Contract - A GMP contract is similar in nature to a fixed price contract, but includes the stipulation that when prices are lower than originally expected, those savings are then passed on to the owner. The contractor's profit is typically set or limited to a specified amount, and when costs increase, that margin is at risk.

4. Unit Price Contract - Though not typically used as a contract between the Owner and the General Contractor, the unit price contract is very common between Generals and their Subcontractors. Basically, a price is attached to each unit of work that is to be 
completed, whether it is square foot of paint or lineal foot of baseboard. This way, the Subcontractor minimizes potential estimating mistakes and is paid exactly what actually gets installed. However, the unit price contract is still susceptible to price fluctuation as increases or decreases could render previously agreed upon unit pricing unrealistic or inaccurate based on current market pricing.

\subsubsection{Related Contractual Language}

Parties negatively impacted by massive cost increases often attempt to invoke the protection of federal and state agencies through various legal doctrines. The legal doctrine most often employed in such situations is the "doctrine of impossibility”. The state of Ohio's doctrine of impossibility, as clarified in Nelson Sand \& Gravel, Inc. v. Ring 2002, resembles that of most state and federal jurisdictions:

Impossibility of performance occurs where after a contract is entered into, an unforeseen event arises, rendering performance by one of more of the contracting parties impossible... A contracting party's nonperformance, however, will not be excused merely because performance would have been difficult, dangerous, or burdensome (Nelson Sand \& Gravel, Inc. v. Ring, 2002-Ohio-6467).

As evidenced by this decision, the courts have shown that price escalation relief is usually not obtainable by those seeking for it under the doctrine of impossibility.

Similarly, another type of contractual protection often sought after is the concept of “force majeure". Tim McGoldrick described this situation as follows:

Those who like clutching at straws will, perhaps, attempt to claim additional costs and time on the grounds of "force majeure". The term does not have any precise meaning or give rise to any special legal doctrine in English law. The one overriding factor is that the event in question must be beyond the control of the party relying on it. Whether an event qualifies for the intended purpose can only be ascertained in light of the general background and terms of the contract using the expression. Different decisions may well be reached on different contracts. As a general statement a "force majeure" clause is not intended to protect the parties from normal risks of a contract, including market price fluctuations. 
Indeed the IChemE Red Book form of contract provides that "the mere shortage of labour, materials, or utilities shall not constitute force majeure unless caused by the circumstances which are themselves force majeure". So shortages caused by

market demand would not constitute force majeure (McGoldrick, 2007).

In essence, neither of these legal doctrines offers much in the way of assistance to those searching for relief from price fluctuation. Additionally, typical contractual language in the various types of contracts mentioned above really succeed only at transferring the risk to perhaps the unknowing, or desperate, other party.

\subsection{Risks Inherent to Contracting}

As mentioned in the introduction, risk has always been a part of contracting in the competitive bid market place. Projects are exposed to risk from initiation to delivery and implementation (Karlsen, 2005). Not surprisingly, these risks are a major source of problems, disputes, delays, and cost overruns in construction projects (Chen, 2000). Despite the inherent danger in doing so, only $12 \%$ of companies surveyed by Fayek used a formal technique to assess project risks and opportunities (Fayek, 1999). Most Contractors base decisions on gut feelings and past experience rather than formal techniques. Typically, Contractors incorporate multiple factors into their pricing to attempt to account for risks they feel they are accepting. Table 2.2 shows the 10 most important factors for both inflation of pricing, and deflation of pricing for time-related risks as determined by General Contractors. 


\section{Table 2-2: Most important inflationary and deflationary factors for pricing time-related risks by general contractors}

\begin{tabular}{|c|c|c|c|}
\hline \multicolumn{2}{|l|}{ Deflation Factors } & \multicolumn{2}{|l|}{ Inflation Factors } \\
\hline Factor & $\begin{array}{c}\text { \% of } \\
\text { Deflation }\end{array}$ & Factor & $\begin{array}{c}\% \text { of } \\
\text { Inflation }\end{array}$ \\
\hline Ideal project cash flow (early receipt of payments) & 38 & $\begin{array}{l}\text { Poor employers reputation to honor } \\
\text { payment on time }\end{array}$ & 35.33 \\
\hline $\begin{array}{l}\text { Good employer's reputation to honor payment on } \\
\text { time }\end{array}$ & 37.25 & $\begin{array}{l}\text { Amount of liquidated damages being } \\
\text { higher than expected }\end{array}$ & 34.67 \\
\hline $\begin{array}{l}\text { Urgent need for work/low to moderate current work } \\
\text { load }\end{array}$ & 35.5 & Poor financial capability of the employer & 34.17 \\
\hline $\begin{array}{l}\text { High intensity of work (high contract value/contract } \\
\text { period) }\end{array}$ & 32.08 & Very tight contract period & 34.08 \\
\hline Sound financial capability of the employer & 32 & $\begin{array}{l}\text { Nonideal project cash flow (late receipt of } \\
\text { payments) }\end{array}$ & 32.75 \\
\hline $\begin{array}{l}\text { Unavailability of works in the market due to poor } \\
\text { overall economy }\end{array}$ & 31.92 & $\begin{array}{l}\text { Large portion of works subcontracted to } \\
\text { nominated subcontractors }\end{array}$ & 31.08 \\
\hline Reasonable contract period with some time buffers & 30.83 & $\begin{array}{l}\text { Low intensity of work (low contract } \\
\text { value/contract period) }\end{array}$ & 27.5 \\
\hline Past/Current Relationship with employer & 29 & $\begin{array}{l}\text { High degree of difficulty (high complexity, } \\
\text { need to adopt special construction method, } \\
\text { likely to have underground obsturctions } \\
\text { and difficult site accessibility, etc.) }\end{array}$ & 27.17 \\
\hline $\begin{array}{l}\text { Past experience in similar project/company strength } \\
\text { in the industry }\end{array}$ & 28.25 & $\begin{array}{l}\text { Onerous contract conditions and rigid } \\
\text { specifications }\end{array}$ & 26.75 \\
\hline Acceptable value of liquidated damages & 26.17 & Possibility to have public objections & 26.75 \\
\hline
\end{tabular}

(Adapted from Chan, 2009)

The results of the above survey indicate that unquantifiable items are considerable justifications for the adjustment of risk buffers in the form of price adjustments. Employer's perceived financial capability and their reputation for honoring payment on time play a critical role in contractors' pricing. This was also supported by Smith and Bohn's survey, which reveals that some contractors account for the reputation of the owner or employer as much as they do for the work itself in determining their pricing (Smith and Bohn, 1999). As evidenced in Table 2.2, "the scale of implication of a single factor can reach $40 \%$ of a contractor's original pricing for these 
time-related risks. Therefore the combination or existence of several favorable factors can cause the contractor's wholly waiving of the costs of possible delaying risks, and on the contrary, a few unfavorable factors can double the pricing” (Chan, 2009). Due to the nature of competitive bidding, this issue becomes a delicate balancing act that must be engaged in by each party in the construction process. Chan went on to say in his findings that "should employers want to obtain more competitive bids to cover the transferred time-related risks, they have to avoid the occurrence of the inflation factors and promote the existence of the deflation factors.” Likewise, contractors must evaluate their personal priorities in reviewing a project for the items listed in Table 2.2, and make their own decisions based on the weighting that they ascribe to the risks and opportunities described.

\subsection{Risks Associated with Price Fluctuation}

The ability to estimate costs accurately is tightly connected to the ability of the estimator to adequately and appropriately analyze and account for risk in the construction process.

Obviously when these costs are subject to change after completion of the estimation, original budgets and numbers are put at risk for inaccuracy. These risks resulting from price fluctuation are two-fold for most contractors:

1. There is the obvious risk of having to absorb the inflated costs.

2. Contractors also risk having to bear the liability should a material shortage cause additional delays to project completion and invoke the possibility of liquidated damages being levied against them (McGoldrick, 2007). 
With average markup on a project being between $10.0 \%$ and $11.9 \%$ (Fayek, 1999), price movements like those seen between 2006 and 2007 (Table 2.1) can cut through project specific profit and into a company's livelihood quickly and effectively.

With that in mind, it has been mentioned that one of the primary goals of each of the parties involved in the construction contract is to minimize and/or transfer risk anywhere and everywhere that they can. However, there are additional, and perhaps unexpected, potential financial ramifications to this practice of risk transferring. In a study that included the simulation of the residential lumber supply chain, the builder required its framing subcontractor to accept the risk for lumber cost fluctuations. Under this type of contract, the framing subcontractor provided a fixed lumber price which could only periodically be adjusted. With the logistics and schedule of everything as they typically are in a construction contract, the subcontractor was required to provide a price today for materials which might not be delivered for much as 20 weeks, but which will not even be ordered for 6 to 16 weeks from the day of contracting. Interestingly, although this lumber pricing policy was developed to reduce the risks of price fluctuations, the simulation results showed that this risk transfer strategy actually induced a risk premium generally in excess of the true commodity at risk. The results also indicated that "the expected return for the homebuilder is highest for the case in which the homebuilder negotiates a lower margin and accepts the commodity price risk directly, rather than transferring this risk to the framing subcontractor/lumberyard” (Walsh, 2004). Especially in cases where cost fluctuations may be expected to be severe, companies' efforts to transfer risk, often motivated by a desire for cost savings, can have unintended consequences that may actually increase overall costs (Walsh 2004). 
An example of the second kind of risk described above can be seen in the steel industry during the first quarter of 2003. Raw steel went from $\$ 300.00$ per ton in that first quarter to $\$ 493.00$ per ton in the second quarter of 2004. Bridge builders in Maryland were unable to hold up their end of the contract with the federal agencies involved in one particular transaction, and the problem was forced into litigation. In the steel contractor's appeals, they made it clear that the potential financial blow of accepting the increased costs would likely delay their work and subsequent work by other contractors (Korman, 2004).

Overall, Contractors and Subcontractors alike consider a wide range of factors when determining their "risk allowance”, or conversely their "opportunity allowance" for a project. These assessments are risky in and of themselves because they are subjective and largely based on the experience of the one reviewing the numbers (Fayek, 1999). Therefore, an item such as price fluctuation that can impact those involved has the potential to create great difficulty within the construction industry.

\subsection{Current Practices for Dealing with the Risk Associated with Price Fluctuation}

With minimal legal protection available to the party accepting the risk for price fluctuation in our current system, companies look for other ways to mitigate potential losses. Assuming that price volatility is here to stay, companies must find ways to increase the legitimacy and accuracy of their project budgets. There are a variety of methods for attempting to deal with this risk that are in regular use today.

1. Contingencies/Reserves - When able, contractors include a contingency (aka reserve) in the project budgets. Contingency is defined as "the amount of funds, budget or time needed above the estimate to reduce the risk of overruns of the project objectives to a 
level acceptable to the organization” (PMI, 2004). A contingency represents additional funding available to account for the possibility and cost of risk. A contingency can range anywhere from 5 to $10 \%$ of the estimated final costs. In an effort to remove the subjectivity from the contingency percentage, additional models besides the traditional percentage method for determining contingency amounts have been widely researched. These include the monte carlo simulation, artificial neural networks, and regression modeling (Baccarini, 2006). However, in standard practices, this number is ultimately subjective, based on a gut feeling, and therefore has several probable weaknesses (Picken, 2001) (Thompson, 1992):

a. This method is in danger of being overly simplistic and heavily dependent on the estimator's faith in his/her own experience.

b. The arrived upon percentage figure is relatively arbitrarily and is likely not appropriate for the specific project it is assigned to.

c. There is a tendency to double count risk, because some other estimators involved in the same project are also likely to include contingencies in their estimates.

d. Finally, the percentage figure still results in a single figure prediction of estimated costs, implying a degree of certainty that may not be justified. (Karlsen, 2005)

2. Project Fast-Tracking - By minimizing project duration, General Contractors and Owners hope to minimize the possibility of prices changing drastically enough to constitute major problems on their jobs. Fast-track scheduling and tilt-up construction are examples of ways that companies are attempting to reduce the timetable for delivery of the construction project. These methods and others similar to these are called "integrated 
project delivery” and are designed to speed up and reduce costs through improved communication.

3. Early Material Procurement/Timely Buyout - Larger contractors are creating preconstruction teams made up of critical trades and suppliers as another form of risk management. These teams attempt to make advance purchases of price-volatile materials to secure pricing as close to the time of project estimation as possible. Agate, Inc., a general contractor in Scottsdale, Arizona, is attempting to minimize their risk associated with fluctuating steel prices by separating the steel package from the rest of the job. They then place the order within an hour of getting a signed contract from the clients (Moore, 2008). However, in this scenario, these Contractors then become responsible for additional storage costs to hold the purchased materials until the project is ready for their installment. The Contractor then accepts this alternative risk of additional storage costs and deals with potential theft and material management problems.

4. Supplier Incentive Programs - This method guarantees the supplier the work when contracts come around as long as they can hold pricing for the Contractor. This option is typically available to high volume builders as suppliers view the consistent purchases as opportunity greater than the risk.

a. Price Cap Contract - This is an example of a supplier incentive program. The concept is broken into three basic agreements between the Supplier and the Contractor.

i. The term of the contract is a relatively long duration, rather than project based. 
ii. The price of the material is capped: if the spot pricing (current market price) is less than the agreed upon price cap, then the Contractor pays the spot price; otherwise, the contractor pays the price cap; and

iii. The contract terms are based on the projected order size of a fixed or average amount every month.

If the Contractor can meet these terms, this type of contract gives him/her a number of benefits:

- The Contractor can minimize the price volatility of the material being purchased.

- The Contractor can use orders from different projects to diversify and meet required order sizes for a given month.

- Longer term contracts often lead to shorter delivery lead times.

- Cost savings can be transformed into lower, more competitive bids.

- The Supplier can increase their market share by signing multiple contracts of this type with local Contractors.

- The supplier can save costs by being better able to forecast business processes such as resource allocation, hiring, maintenance, and capacity expansion/contraction (NG, 2003).

5. Price Adjustment (Escalation) Clause (PAC) - Perhaps the most complex but potentially effective way for dealing with this risk of price fluctuation is the inclusion of a PAC in the project contract. The following section reviews the specifics of the PAC and how it is used in the industry today. 


\subsection{Price Adjustment Clauses}

\subsubsection{History of the PAC}

The PAC is used to pass unexpected or extreme price increases onto the consumer in a manner that is acceptable and agreed upon during the contracting phase of a construction project. The contract should clarify the procedure for calculating this adjustment in order to avoid additional disputes. This type of a clause has the potential to protect both sides of a contractual agreement in case of material or labor price fluctuations. In Keller’s paper entitled, “Optimal Policies for Claiming Payment Under Price Escalation Clause Types of Contracts”, he gave the following brief history on the PAC:

[PAC] originated in the U.K. during World War II. The original premise was that with the Government controlling wage rates and material costs, escalation of costs on these elements was outside the contractor's control and should be reimbursed on a net cost basis. This practice continued in the U.K. after the war and became progressively more sophisticated.

In January 1968, the Economic Development Committee for Building approved a steering group on Price Fluctuation. The terms of the reference of this committee were to assess the cumbersome practice of claims for [PAC]. This practice required the contractor to submit complete details relating to the work for which he was claiming [PAC]. These details included labor, materials, overheads, and a considerable effort was required to check and substantiate them. The committee was accordingly asked to devise simple formulae which only took account of labor and materials indices and the period of time over which the contract was carried out (Economic Development Committee for Building, 1974)

Since this time, PAC's have become common in certain federal and state contracts. Highway departments commonly use PACs for asphalt, paving, steel, cement, and diesel fuel. After rapid price increases of Hot Mix Asphalt (HMA) negatively impacted Washington State’s Department of Transportation (WSDOT) in 2006, they decided to implement a HMA escalation clause in September of that year. In the first year, 15 contracts had been awarded that contained the clause. By including this clause, uncertainty for WSDOT and for their contractors has been removed. "WSDOT gets bid prices that actually reflect current market values, rather than a price 
that factors in possible future cost increases for the material. WSDOT's clause allows for either a payment to the contractor or a credit to WSDOT if the asphalt binder monthly cost index increases or decreases $10 \%$ or more between the month preceding the bid date and the month that the HMA was placed” (Measures, Markers, and Mileposts, 2007).

\subsubsection{Problems with PAC's}

The difficulty with drafting a PAC lies in a number of the details necessary for creating an effective and fair clause. According to Choi’s paper entitled, A Study on the Price Escalation system in a Construction Contract, the primary arguing points in relation to these clauses are as follows:

1. What is the Minimum Fluctuation Rate (MFR)? Meaning, at what fluctuation rate does the clause take effect? Is a 5\% change in price adequate to execute the clause?

2. What method should be used to calculate the MFR? There are a number of possible "triggers" or indices that can be used to calculate the MFR. With each of these indices, a percentage can be determined based on the original pricing versus the increased cost at the time of installation and clause execution becomes dependent on meeting or exceeding that agreed upon percentage. Functional indices could be based on any of the following items:

a. Total Cost of Construction (Choi, 2006)

b. The "invoice method" - Contractor uses documentation in the form of invoices to substantiate the changes in material pricing from the time of contracting to the time of actual purchase (Berenson, 2005).

c. The "index method" - This method activates the clause based on changes reflected in a designated price index guide (Berenson, 2005). A wide variety of 
indices are available that could be used in this calculation depending on the location, type, and size of the project. Possible macro-economic indices that could be considered would be the Consumer Price Index, or the Producer Price Index. More construction specific indices that could be utilized would be a Construction Cost Index, or a material specific index such as lumber, fuel, asphalt, or copper.

d. Combination method - An additional option would be the hybrid combination of the invoice and the index method. This method would require the Contractor and Owner to agree to a "certified bid cost", in which the "contractor discloses his estimate of the raw material costs based on then-current supplier prices or an index price listing. If the supplier’s actual price has increased by more than a [certain percentage] from the certified bid cost, the increase gets added to the contract price.” (Williams, 1994)

3. What initial date in the project becomes the date for pricing comparisons throughout the project?

These arguing points were reviewed, and 10 primary items of contention with the price escalation system were drawn out of Choi's various discussions with coauthors and interviews with experts. The questions along with the results and response rates of Choi's survey are contained in Table 2-3. 
Table 2-3: Results on issues in contract price escalation

\begin{tabular}{|c|c|c|}
\hline Question & Replies & $\%$ \\
\hline $\begin{array}{l}\text { Indicator to determine the MFR (minimum } \\
\text { fluctuation rate) }\end{array}$ & $\begin{array}{l}\text { Fluctuation rate of consumers price index } \\
\text { Fluctuation rate of construction price index } \\
\text { Average profit rate of constructors }\end{array}$ & $\begin{array}{l}57.1 \\
35.7 \\
7.1\end{array}$ \\
\hline $\begin{array}{l}\text { Optimum level of the MFR that enables to } \\
\text { request the price escalation }\end{array}$ & $\begin{array}{l}5 \% \\
3 \% \\
10 \%\end{array}$ & $\begin{array}{l}35.7 \\
57.1 \\
7.1\end{array}$ \\
\hline Initial date in reckoning the price fluctuation & $\begin{array}{l}\text { Design completion date } \\
\text { Bidding date } \\
\text { Contract signing date }\end{array}$ & $\begin{array}{l}42.9 \\
42.9 \\
14.3\end{array}$ \\
\hline Method to calculate a fluctuation rate & $\begin{array}{l}\text { FRCA (flucuation rate for the categories of articles) } \\
\text { FRI (fluctuation rate for index) }\end{array}$ & $\begin{array}{l}64.3 \\
35.7\end{array}$ \\
\hline $\begin{array}{l}\text { Specifying the method to calculate the } \\
\text { fluctuation rate in a contract document }\end{array}$ & $\begin{array}{l}\text { Necessary } \\
\text { Unnecessary }\end{array}$ & $\begin{array}{l}92.9 \\
7.1\end{array}$ \\
\hline Reasonable deduction rate & \begin{tabular}{|l|}
$0 \%$ (unnecessary) \\
$1 \%$ \\
$1.5 \%$ \\
$2 \%$ \\
$3 \%$
\end{tabular} & $\begin{array}{l}35.7 \\
7.1 \\
7.1 \\
21.4 \\
28.6\end{array}$ \\
\hline Minimum elapsed period & $\begin{array}{l}30 \text { days } \\
60 \text { days } \\
90 \text { days } \\
120 \text { days } \\
180 \text { days } \\
1 \text { year }\end{array}$ & \begin{tabular}{|l|}
7.7 \\
38.5 \\
23.1 \\
15.4 \\
7.7 \\
7.7 \\
\end{tabular} \\
\hline Progress rate to be adopted in price escalation & $\begin{array}{l}\text { Actual progress rate } \\
\text { Scheduled progress rate }\end{array}$ & $\begin{array}{l}28.6 \\
71.4\end{array}$ \\
\hline Overhead and profit in price excalation & $\begin{array}{l}\text { Include } \\
\text { Exclude }\end{array}$ & $\begin{array}{l}85.7 \\
14.3\end{array}$ \\
\hline Advance paymnet in price escalation & $\begin{array}{l}\text { Necessary to deduct } \\
\text { Unnecessary to deduct }\end{array}$ & $\begin{array}{l}92.9 \\
7.1\end{array}$ \\
\hline
\end{tabular}

(Adapted from Choi, 2006)

The price adjustment clause is a proven method that effectively shares the risks associated with price fluctuation between two parties to a contract. However, in order to be effective, the various questions listed in Table 2.3 should be clarified and answered by those entering into the contract to insure that there is an equal understanding and acceptance of the terms and conditions of the

PAC. 


\section{METHODOLOGY}

\subsection{The Method}

It is the intent of this research to discover methods currently in use for dealing with price volatility in the construction market. Additionally, the results provide valuable information regarding how the various parties involved in the construction process feel about the available and practiced options. Because one of the desired outcomes of this thesis project is the discovery of the opinions of industry experts, the research was done through a series of Delphi rounds. The Delphi method is "a structured process for collecting and distilling knowledge from a group of experts by means of a series of questionnaires interspersed with controlled opinion feedback" (Adler and Ziglio, 1996). This method will facilitate the discovery of the methods used and opinions held by the industry experts in each of the categories being surveyed. According to Norman Dalkey, member of the RAND institute and founder of the Delphi Method, there are three basic features supporting the validity of this method:

1. Anonymous Response - opinions of the group are obtained by formal questionnaire. Anonymity is maintained between panel members, not between panel members and the researcher.

2. Iteration and Controlled Feedback - interaction is effected by a systematic exercise conducted in several iterations, with carefully controlled feedback between rounds.

3. Statistical Group Response - the group opinion is defined as an appropriate aggregate of individual opinions in the final round (Dalkey, 1969). 
In essence, by being able to adjust future surveys based on previous round outcomes, it allows for the flexibility necessary to methodically refine results in an effort to determine the most likely answer to the research question.

The Delphi Method is made up of the following basic steps:

1. Selection of a panel to participate in the exercise. Customarily, the panelists are experts in the area to be investigated.

2. Development of the round 1 questionnaire.

3. Testing the questionnaire for proper wording (e.g., ambiguities, vagueness)

4. Transmission of the round 1 questionnaire to the panelists.

5. Analysis of the round 1 responses.

6. Preparation of the round 2 questionnaire (and possible testing).

7. Transmission of the round 2 questionnaire to the panelists.

8. Analysis of the round 2 responses (Steps 6 to 8 can be repeated for future rounds as long as desired or necessary to achieve stability in the results).

9. Preparation of the consensus and conclusions.

Because panelists are surveyed individually, the Delphi Method offers various advantages over the conventional face-to-face conference as a tool for gathering opinions. Helmer and Rescher, two of the founders of the method, proclaimed the advantages of the Delphi technique over standard expert panels based on its ability to “eliminate committee activity altogether, thus further reducing the influence of certain psychological factors, such as specious persuasion, the unwillingness to abandon publicly expressed opinions, and the bandwagon effect of majority opinion. This technique replaces direct debate by a carefully designed program of sequential individual interrogations (best conducted by questionnaires) interspersed with 
information and opinion feedback derived by computed consensus from the earlier parts of the program. Some of the questions directed to the respondents may, for instance, inquire into the reasons for previously expressed opinions and a collection of such reasons may then be presented to each respondent in the group, together with an invitation to reconsider and possibly revise his/her earlier estimates. Both the inquiry into the reasons and subsequent feedback of the reasons adduced by others may serve to stimulate the experts into taking into account considerations they might through inadvertence have neglected, and to give due weight to factors they were inclined to dismiss as unimportant on first thought.” (Helmer and Rescher, 1959) Furthermore, the anonymity intrinsic to the questionnaire allows for unbiased responses void of groupthink and personal opinion influence (Martino, 1983). The Delphi method was chosen because it is an effective tool for obtaining the desired results of this research project.

\subsection{The Process}

\subsubsection{Step One - Selection of the Panel Members}

The validity of each panel member's input and opinions is critical to ensure accurate results from the research. Panel members were selected from a list of pre-qualified candidates considered representative of each party in the construction process. To have been considered for the initial survey population, each candidate must be a member of one of Utah's various national Association of Home Builders (NAHB) affiliated home builders associations. The NAHB is a recognized trade association that has been promoting government policies that make home building a priority since 1942 (NAHB, 2010). There are seven home builders associations in Utah that respondents were selected from. Since a broad perspective from all parties involved in 
the construction industry was desired, panel members have been selected from the following disciplines:

- General Contractor

- Subcontractor

- Suppliers

The selected general contractors represent construction companies in Utah who have a high level of residential experience. Similarly, the selected subcontractors and suppliers represent companies currently doing business in Utah's residential construction industry. There was no distinction made regarding the specific trade/expertise of the qualifying subcontractors and/or suppliers. Lists of potential respondents were created using the various NAHB member associations’ on-line directories. The survey population included 506 general contractors, 674 subcontractors, and 333 suppliers. Each potential respondent was assigned a number and reordered based on a random number generator to create a panel that included a range of opinions from throughout Utah. The panel was ultimately determined by contacting this re-ordered list of potential respondents until the recommended number of panel members had been achieved. In accordance with proven Delphi Methodology, this research utilized a panel of 15-20 respondents, or 6-7 experts from each of the 3 categories (Ludwig, 1997). See appendix A for the list of the randomly selected panel members.

\subsubsection{Step Two - Development of the Round 1 Questionnaire}

The goal of the first round of questions was to gain an understanding of the positions of the panel members, as well as to find out what type of contracts are typically being used by the panel. Questionnaires have been formulated using multiple types of questions in order to retrieve this information. A Likert Scale (Likert, 1932) was utilized for a good portion of the 
questions to allow for quantification and comparison of panel member opinions. Additionally, multiple-choice and open-ended questions were used. The questions were designed to extract opinions, knowledge, and data based on the objectives of the research. Information from the literature review, and recommendations from the research committee were used to form the basis of the questions. In order to avoid limiting the information that could be shared, certain questions have extra space provided to allow panel members to write in their own thoughts, thus allowing for additional information to be gained. See Appendix B for the first round statements/questions survey.

\subsubsection{Step Three - Testing the Questionnaire}

The statements/questions underwent various revisions before receiving committee approval. They were then tested by being given to the first 5 potential respondents from the list obtained in step one. Received responses were reviewed in order to validate effectiveness of each question at obtaining the desired information. Additional revisions were made based on the sample survey, and final statements were deemed adequate to ensure retrieval of accurate data.

\subsubsection{Step Four - Transmission of the Round 1 Questionnaire}

After completing the process of creating the round 1 questionnaire, it was submitted to the selected panel members. Answers were obtained in two ways. Some respondents were able to complete the questionnaire through individual conversations over the telephone in which each question was asked and responses were recorded, including additional comments as necessary. Other respondents were e-mailed a copy of the questionnaire following a brief telephone request, and completed and returned it in the same manner. The author conducted all of these telephone interviews. 


\subsubsection{Step Five - Analysis of the Round 1 Responses}

Upon completion of the first-round survey, the data was collected, organized, and analyzed. Responses were categorized and analyzed by each industry party to enable determination of overall preferences for each of the three parties. The data for each statement was collected and organized in a spreadsheet so that the mean, median, and mode could easily be calculated for each category of industry participant. Tables detailing the data collection are included in Chapter 4 of this paper.

\subsubsection{Step Six - Preparation of the Round 2 Questionnaire}

The second-round questions were generated upon completion of the data analysis detailed above. Based on the responses received from the first round, the round 2 questionnaire was designed to share pertinent results, including, in some cases, the other respondents' opinions. Additionally, the second-round survey was utilized to request more information on current practices, based on the results of round 1 . In the second round, panel members had an opportunity to reconsider and/or confirm their previous responses to ensure overall accuracy. A few new generalizing statements were added to gather additional knowledge based on the statements and results of the first round. See Appendix C for the second round statements/questions survey.

\subsubsection{Step Seven - Administration of the Round 2 Questionnaire}

The second-round questions were transmitted to the all panel members in the same manner as the first round.

\subsubsection{Step Eight - Data Analysis}

The results of rounds 1 and 2 were organized and summarized. Data collation and analysis were conducted to compare different individual party responses with overall averages. 


\section{FINDINGS}

This chapter details the findings produced by the various Delphi rounds conducted for this research. Forty-two potential panel members were contacted with a response rate of 45 percent. Responses were ultimately received from a total of 19 panel members. The panel consisted of 7 general contractors, 6 subcontractors, and 6 suppliers (see Appendix A for a list of responding panel members). The response rate for the panel was 100 percent for round 1, and 95 percent, or 18 of 19 panel members, for round 2 of the questionnaires. As the objectives of the research were achieved following the second-round of the Delphi method, no further rounds were conducted.

The results of the questionnaires have been divided into 5 categories based on the type of information gathered by the various questions. The categories are: 1) panel member company background; 2) current contracting methods; 3) current practices for dealing with price fluctuation; 4) risk allocation of the various practices; 5) issues faced when prices are decreasing. The round 1 questionnaire (see Appendix B) was comparatively broad in scope, requesting a wide range of information from the panel members and utilizing primarily open-ended questions to allow for the potential unanticipated answer. The round 2 questionnaire (see Appendix C) was used to clarify and focus on the answers received during round 1, allowing for a more accurate view of current practices and the various parties' dispositions towards them. Use of round 2 in this fashion allowed for increasingly valid and conclusive results from the panel members. 


\subsection{Panel Member Company Background}

In order to better understand the nature of the companies on the panel, a few questions were included in the survey that asked the panel members for information regarding the size and volume of their respective companies. Company background questions differed based on the respondent's self-categorization as a general contractor, subcontractor, or supplier. Due to the relatively small sample size typical of the Delphi method, this section includes tables incorporating the answers to the background questions for each of the 19 respondents.

General contractors were asked for the number of homes they built in the last calendar year (May 2009 - May 2010). Additionally, the average price of those homes was requested. The following table details these results for each respondent in the general contractor category.

Table 4-1: General contractor respondents' company information

\begin{tabular}{|l|c|c|c|c|c|c|c|}
\cline { 2 - 7 } \multicolumn{1}{c|}{} & Resp \#1 & Resp \#2 & Resp \#3 & Resp \#4 & Resp \#5 & Resp \#6 & Resp \#7 \\
\hline $\begin{array}{l}\text { \# of } \\
\text { Homes } \\
\text { Built (last } \\
\text { calendar } \\
\text { year) }\end{array}$ & $1-10$ & $1-10$ & $1-10$ & $11-50$ & $51-100$ & $1-10$ & $1-10$ \\
\hline $\begin{array}{l}\text { Avg. Price } \\
\text { of Homes } \\
\text { (\$1,000’s) }\end{array}$ & $500-1000$ & $200-300$ & $1000+$ & $100-200$ & $100-200$ & $500-1000$ & $200-300$ \\
\hline
\end{tabular}

Five of seven respondents built 1-10 homes. The median price range of homes built by the surveyed general contractors was \$200,000-300,000.

Panel members who were subcontractors were asked to approximate the number of homes they performed work on, and what the average price of those homes were. The following table details results for each respondent from the subcontractor category. 
Table 4-2: Subcontractor respondents' company information

\begin{tabular}{|l|c|c|c|c|c|c|}
\cline { 2 - 6 } \multicolumn{1}{c|}{} & Resp \#1 & Resp \#2 & Resp \#3 & Resp \#4 & Resp \#5 & Resp \#6 \\
\hline $\begin{array}{l}\text { \# of Homes } \\
\begin{array}{l}\text { Worked in } \\
\text { last } \\
\text { calendar } \\
\text { year) }\end{array}\end{array}$ & $51-100$ & $201-500$ & $11-50$ & $500+$ & $11-50$ & $51-100$ \\
\hline $\begin{array}{l}\text { Avg. Price } \\
\text { of Homes } \\
\text { (\$1,000's) }\end{array}$ & $1000+$ & $100-200$ & $300-500$ & $200-300$ & $500-1000$ & $100-200$ \\
\hline
\end{tabular}

Finally, panel members in the supplier category were asked to approximate the number of homes for which they supplied materials during the last calendar year. The following table details the supplier respondents' answers.

Table 4-3: Supplier respondents' company information

\begin{tabular}{|l|c|c|c|c|c|c|}
\cline { 2 - 6 } \multicolumn{1}{c|}{} & Resp \#1 & Resp \#2 & Resp \#3 & Resp \#4 & Resp \#5 & Resp \#6 \\
\hline $\begin{array}{l}\text { \# of Homes } \\
\text { Materials } \\
\text { were } \\
\begin{array}{l}\text { Supplied to } \\
\text { (last } \\
\text { calendar } \\
\text { year) }\end{array}\end{array}$ & $500+$ & $500+$ & $201-500$ & $51-100$ & $500+$ & $201-500$ \\
\hline
\end{tabular}

As evidenced by the data, the respondents that make up the panel for this research perform work in various price ranges, and in varying volumes.

\subsection{Current Contracting Methods}

Panel members were also asked to share the type of contract(s) that they primarily use in the current market. Included in this section are a number of graphs showing the average use of each type of contract divided by panel member categorization. It should be noted that these 
numbers do not reflect the average of total projects being done under each type of contract, as it has been shown that some of these companies do a much higher volume of business under their preferred contract. These numbers $d o$, however, represent the average use of each contracting method, per company, based on the panel members' responses. Also included in this section, are the results for a question on the survey that requested current panel member practices for increasing pricing to compensate for potential price fluctuation. Respondents were asked what percentage they added to bids to compensate for this risk in the following categories:

- Materials

- Labor

- Equipment - (gas prices, rentals, etc.)

- Subcontracts

- Other - (i.e. county permits and fees, engineering, etc.)

Responses were requested for each type of contract that the panel member had experience with.

General Contractor. The chart below shows the average use of each type of contracting method for the general contractors surveyed. Of those surveyed, general contractors working in Utah's residential construction market utilizes a fixed price contract for the majority of their work (54\%). The remaining work is divided closely between unit price (24\%) and cost plus (21\%) contracts, with the minor remainder being guaranteed maximum price contracts (1\%). See the figure below: 


\section{Table 4-4: Average use of contracting methods for general contractors surveyed}

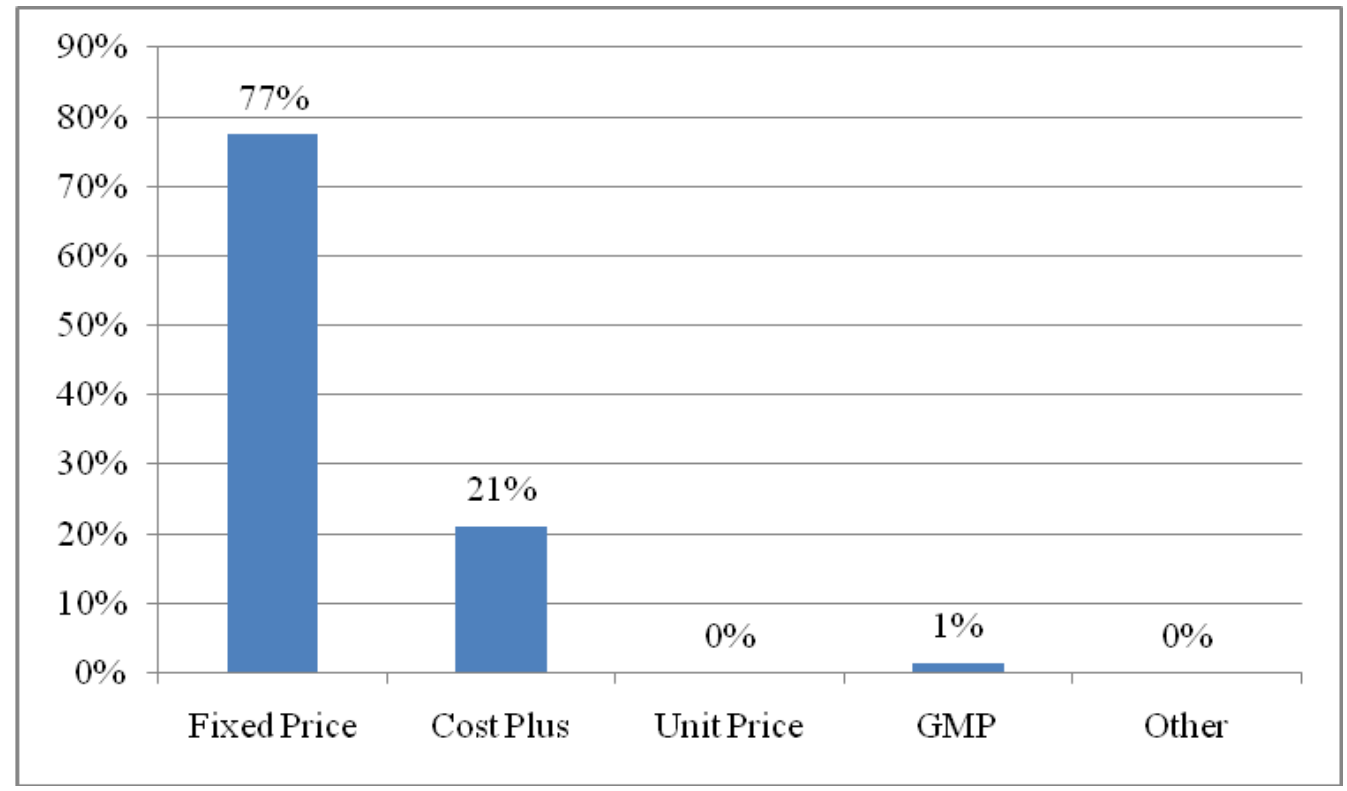

Further analysis of this data revealed additional information regarding current contracting trends not evident when viewed as an average. Four of five general contractors on the panel who built 1-10 homes in the last calendar year used fixed price contracts on average 86 percent of the time. The one anomaly in that volume range is a high end custom builder who does 85 percent of their business under cost plus contracts. According to this respondent, they are able to do the majority of their contracts as cost plus because of their proven and long-standing reputation for honesty and integrity. This reputation allows clients to feel comfortable entering into what is often considered a potentially risky type of contract from an owner's perspective. However, as evidenced by the remainder of the panel responses, the ability of this general contractor to perform the majority of their work under a cost plus contract is atypical to the rest of the industry. 
On the higher volume side of the panel, the two general contractors surveyed actually reported that an average of 83 percent of their business was done under unit price contracts. Both of these companies own, develop, and build out their projects. Therefore, contracts with the end-users are based solely on current market pricing, independent of the actual costs incurred during construction. Despite originally being viewed as unit price contracts by the respondents due to the fact that their pricing is based on the type of unit for sale, the contracts were ultimately categorized as fixed price because they any single residence is offered to buyers at a fixed price. This difference resolves the discrepancy in contracting methods displayed in the data between the low and high volume builders.

When asked if the percentages of types of contracts used had changed in the past 5 years, 4 of the 7 general contractors stated that they had. Two builders reported an increasing percentage of jobs being done under cost plus contracts instead of fixed price contracts. These companies cited recent owner willingness to take on additional risk in order to take advantage of potential savings as the reason for this observed change. One respondent reported a recent increase in fixed price contracts due to owners fearing unpredictable material price volatility.

As mentioned above, company bidding practices with regards to price fluctuation were also requested from the general contractors on the panel. Six of the seven builders surveyed reported increasing their bids to lessen the risk of potential price fluctuation in at least one of the categories listed above in the introduction to section 4.2 (materials, labor, equipment, subcontractors, other). One respondent did not answer this question. The data shows that the biggest percentage increase occurs with material costs, ranging from 4-8 percent increases between the various types of contract methods, with an average increase of 6 percent. Following material increases, the next greatest increase reported by the panel was to cover the risk of 
subcontractor prices increasing. This data ranged from 3-6 percent. As expected, cost plus contracts showed the smallest average amount of increase added to cover the risk of price fluctuation (2\%), and fixed price contracts showed the greatest average amount of increase in each of the categories (5\%). The following two figures contain the average percentage increases reported by general contractor, subcontractor, and supplier panel members for each category, and separated by contracting method:

Table 4-5: Average percent increase added to materials and labor to cover potential price fluctuation

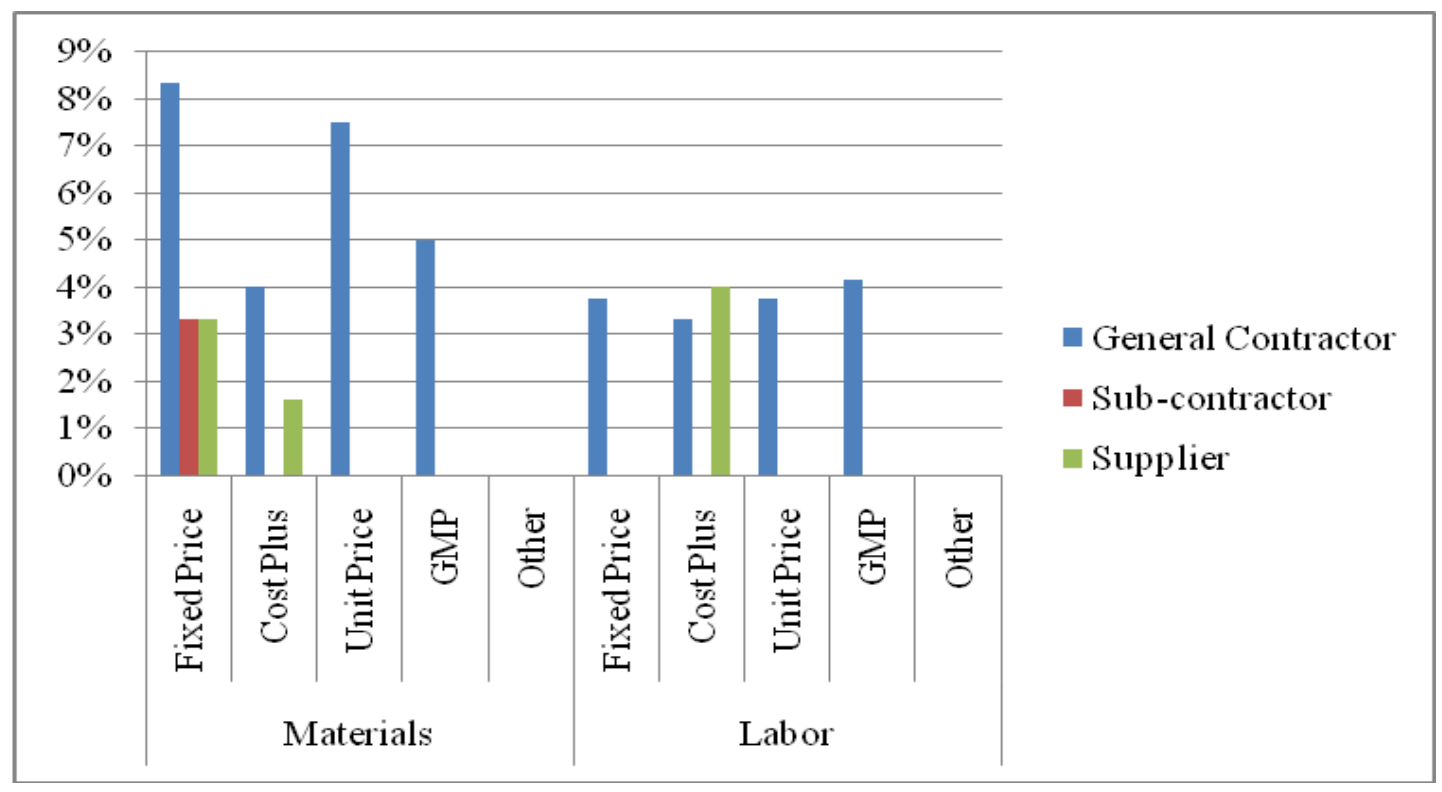


Table 4-6: Average \% increase added to equipment, sub-contractors, and other items to cover potential price fluctuation

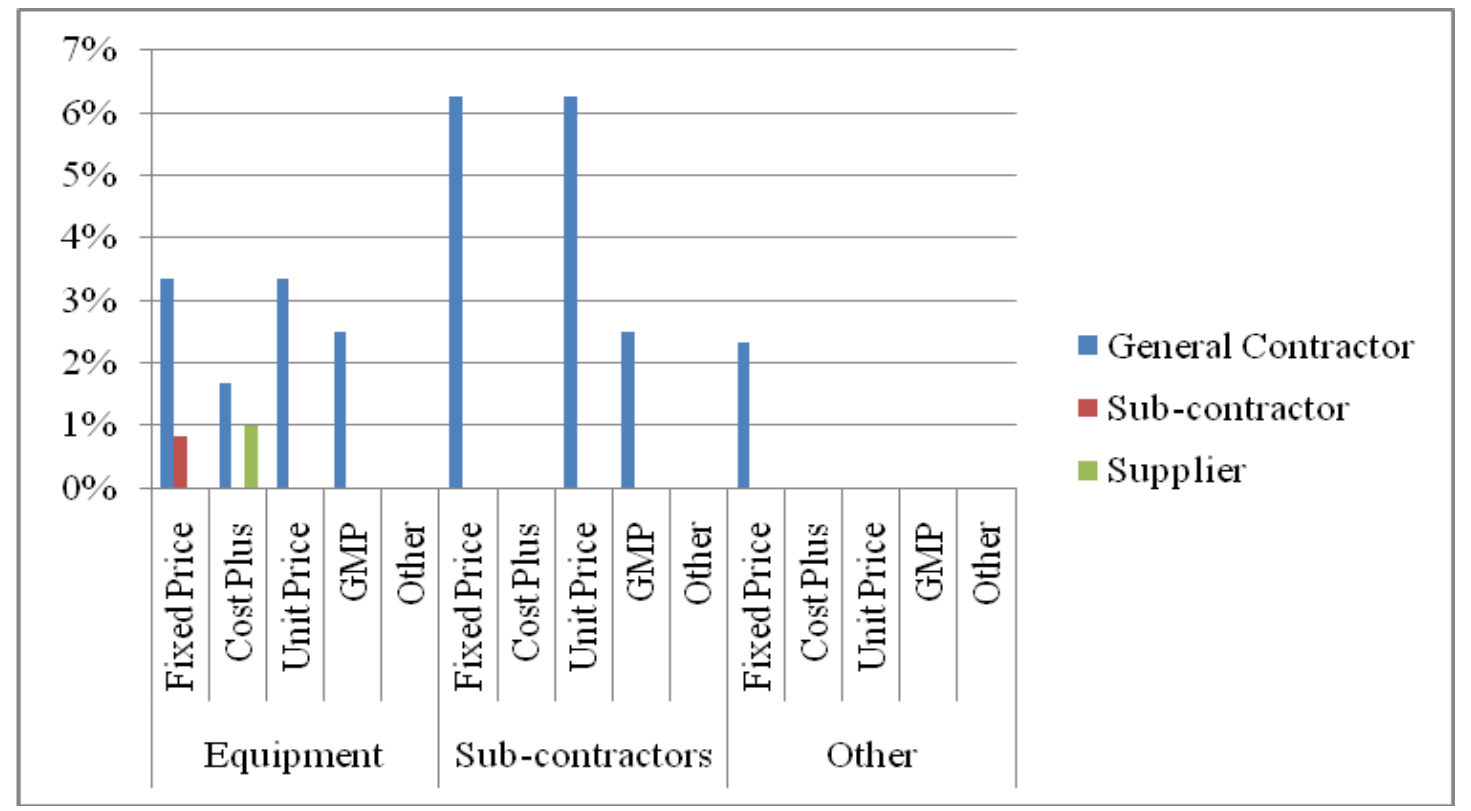

Subcontractor. According to the data gathered, subcontractors also worked primarily with fixed price contracts. On average, sub-contractor panel members used fixed price contracts 81 percent of the time. The remaining work was done under unit price (17\%) and cost plus (2\%) contracts. The following chart details these results. 
Table 4-7: Average use of contracting methods for subcontractors surveyed

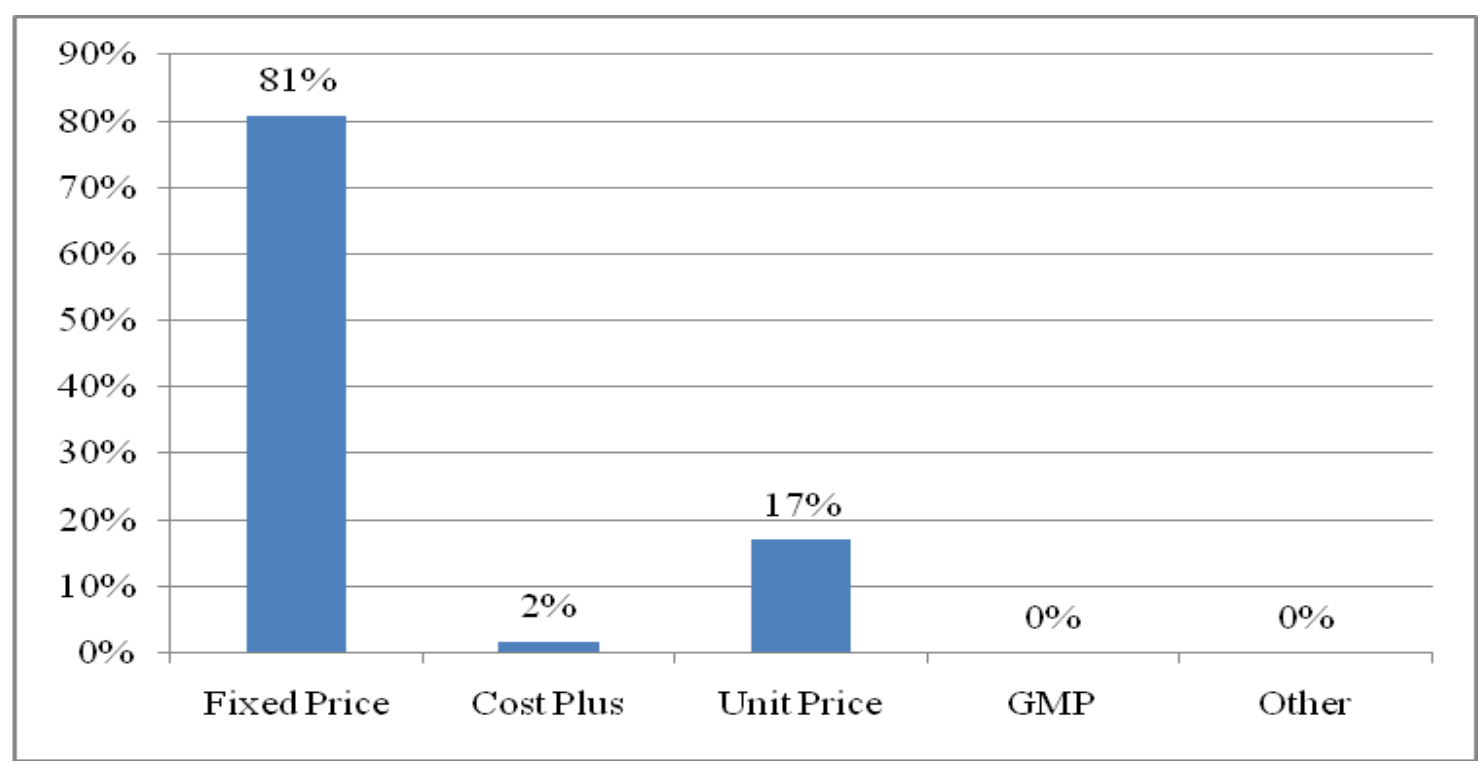

It should be noted that these numbers change substantially when one outlier company is removed from the equation. A concrete staining contractor that was part of the panel does 100 percent of their work based on square foot pricing, or unit pricing. Removing this respondent from the survey shows a very different picture. The average use of fixed price contracts by the remaining 5 sub-contractors is 97 percent. No respondents reported a change in their contracting methods over the past 5 years.

Sub-contractors were also asked about company bidding practices with regards to price fluctuation. Like the general contractors, this category of respondents was asked what percentage they add to bids to compensate for the risk of price fluctuation on materials, labor, equipment, and/or sub-contractors. Responses were again requested for each type of contract that the panel member had experience with. Four of the six sub-contractors reported no increase to compensate for the risk of price fluctuation, or 0 percent in every category. The data shows that the materials category received the highest reported percentage increase (3\%). However, the 
median percentage in this set of data was still 0 percent. The only other category that showed an increase was in equipment. One of six respondents stated that they included a 5 percent increase on equipment costs to compensate for potential fluctuation in the price of gas. The other 5 respondents reported 0 percent for equipment. See Table 4-5 and Table 4-6 above containing the average percentage increases reported by sub-contractor panel members by category, and by contracting method.

Supplier. This category of respondents more often used cost plus type contracts in their businesses than any other (63\%). The remainder of contracts used by suppliers was made up of fixed price (36\%) and unit price contracts (1\%). See the following figure:

\section{Table 4-8: Average use of contracting methods for suppliers surveyed}

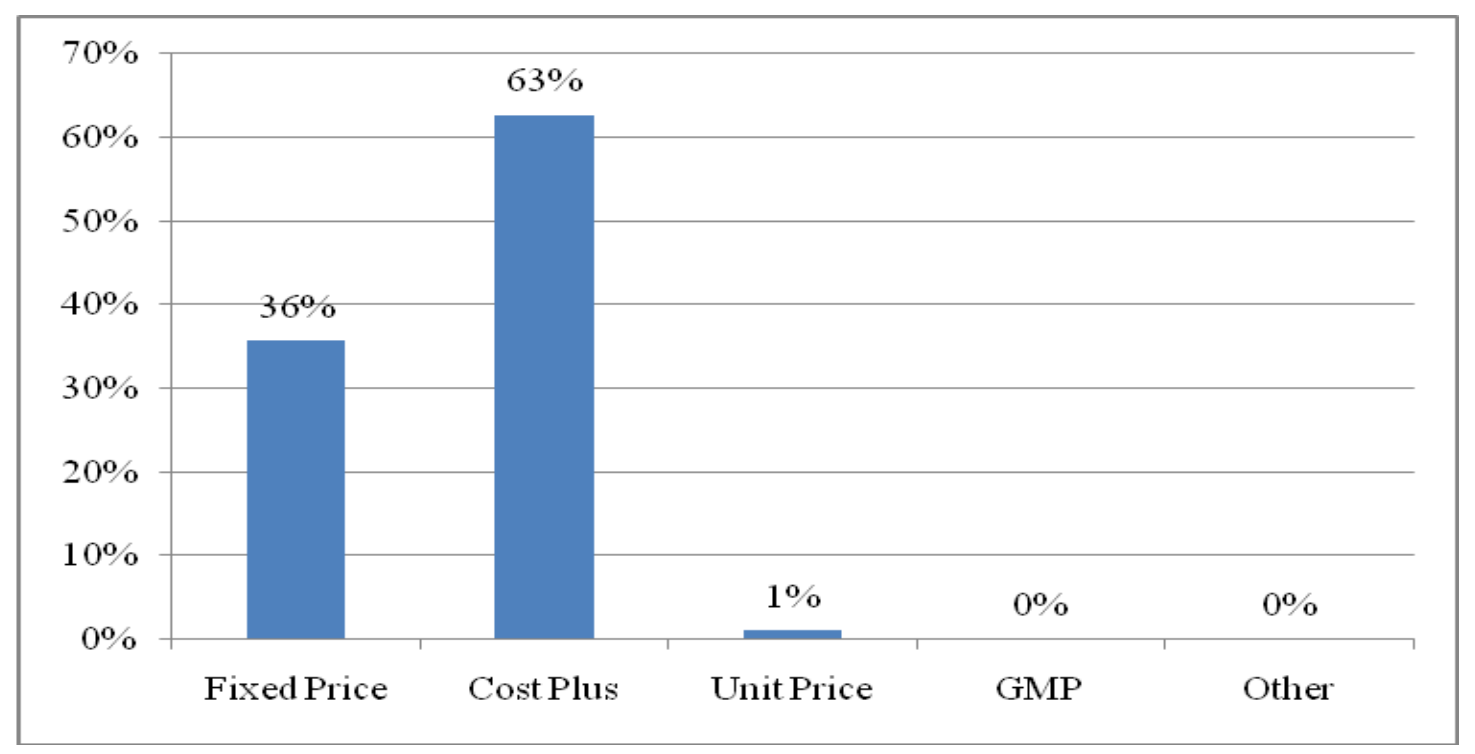

Of the 6 respondents, 2 used fixed price contracts 99.5 percent of the time, and the remaining 4 used cost plus contracts 94 percent of the time for their respective businesses. It should be noted that what suppliers categorized as cost plus contracts, could technically be described as fixed 
price contracts and there is some question remaining as to the complete accuracy of this data. However, as this data is peripheral to the research objectives, the data will be left as received from the panel members.

When asked if the percentages of types of contracts used had changed in the past 5 years, every panel member in the supplier category responded in the negative. It seems that both suppliers and subcontractors are far enough removed from the end-user market that they are better able to control the types of contracts that they enter into. One respondent stated that contract type usage had not changed, and that it was "our choice to stay that way".

Suppliers were also asked what percentage they add to bids to compensate for the risk of price fluctuation on materials, labor, equipment, and/or sub-contractors. Responses were again requested for each type of contract that the panel member had experience with. 3 of the 6 suppliers reported no increase to compensate for the risk of price fluctuation, or $0 \%$ in every category. 2 of the remaining 3 reported increasing materials costs by an average of $9 \%$ to compensate for the risk of price fluctuation. The third respondent showed an increase of $20 \%$ in the labor category. See Table 4-5 and Table 4-6 above containing the average percentage increases reported by supplier panel members by category, and by contracting method.

\subsection{Current Practices for Dealing with Price Fluctuation}

In the first round of the questionnaire, panel members were asked an open-ended question requesting the top 3 methods that each company currently utilizes for dealing with the risk of price fluctuation. Answers were compiled and grouped into 6 different applicable categories. Here are the categories along with examples of actual responses assigned to each: 
1. Timely buyout of contracts - Payment for materials and/or services up front, prior to needing them on the job to guarantee pricing. Responses included:

- Owners/builders pay for materials up front, like copper pipe.

- Pre-purchase large items, tagged in the shop for particular jobs. Allows us to leave decisions about upcoming prices changes to owners.

2. Contract language - Any kind of contract language including escalation clauses, bids with time limits, etc., attempting to protect one’s company from the risk of price fluctuation. Responses included:

- Bids with expiration dates.

- Use of an escalation clause and allowances.

3. Inventory management - Focused management of inventory by stockpiling, high volume purchases, independent manufacturing of product, etc. Responses included:

- Lock in prices with volume purchases on a national scale.

- Maintain inventory on volatile items. Buy minimal amounts when prices are high, stockpile when prices are low.

4. Bid increases - Inclusion of percentage increase in bid to protect against potential future increases in prices. Responses included:

- Add a percentage to bids to account for some of the risk.

- Percentage increase on fixed price contracts, based on overall job cost.

5. Relationships with subs/suppliers - Maintaining good and adequate relationships with subs and suppliers to help share the risk between multiple parties. Responses included:

- Selling products that are supplied to us by our longstanding core vendors.

- Maintain close contact with suppliers. Hold regular price sheet reviews. 
6. Accelerated Schedule - Implement techniques to lessen the time between bid acceptance and contract completion in an attempt to minimize exposure to price fluctuation. There was only one response included in this category. The response is included below:

- Schedule quickly after signing contracts.

Due to the fact that some respondents did not supply the requested 3 methods with their responses, the total number of answers received from the entire panel was only 46. Each of the 46 answers was assigned to one of the categories above and the top 5 responses were then used in the second questionnaire to further clarify current practices. "Bid increases" was removed after further discussion due to the perception by the majority of the panel that they are generally unable to increase bids in today's market if they still want to win contracts. In its place, "bid expiration dates" was broken out of the "contract language" category due to the number of responses from round 1 that mentioned this type of contract language specifically. Round 1 showed that "inventory management" was utilized to control the risk of price fluctuation more than any other method. Sixteen of the forty-six answers (35\%) received fell into this category. The next two highest categories had 9 responses each, and were "timely buyout of contracts", and "contract language". These two categories both individually received $20 \%$ of the given responses. The next most common response was "relationships with subs/suppliers" with 8 responses (17\%), followed by “bid increases” with 3 (7\%), and “accelerated schedule” with only 1 response (2\%). Additional response received in relation to the "accelerated schedule" category pointed out that panel members are working as quickly as possible regardless of price fluctuation implications. The figure on the following page specifies the aggregate number of responses given by the entire panel in Round 1 for each category. 
Table 4-9: Total number of responses per price

fluctuation management method

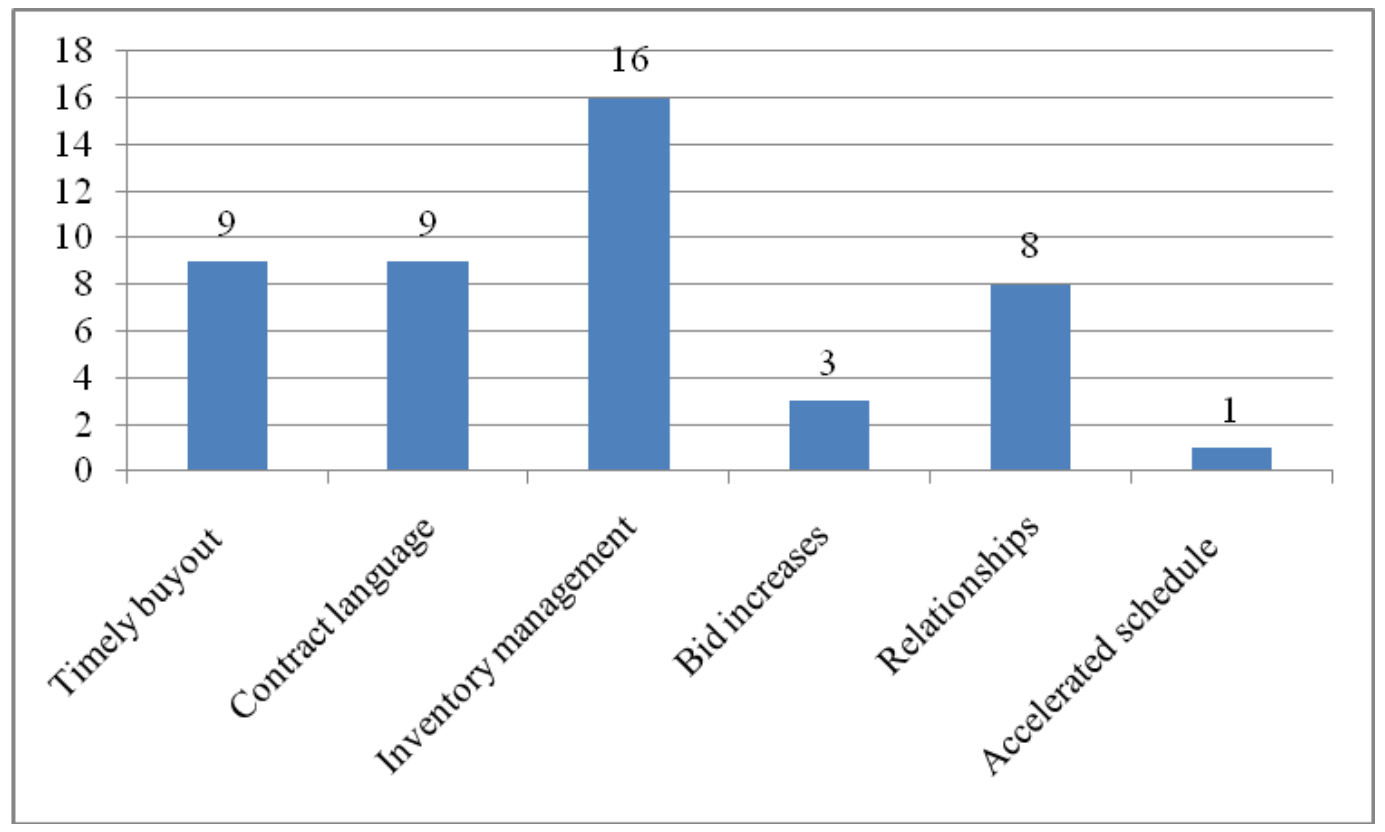

In order to further clarify the results obtained from Round 1, the panel was asked during Round 2 to rank the top five methods given in Round 1, in order of effectiveness at managing the risk of price fluctuation. A ranking of 1 signified what panel members felt was the most effective of the methods, and a rating of 5 was given to what was perceived to be the least effective of the methods. It was decided that the contract language category would be divided into two options for the panel to pick from. The following list details the five practices given to the panel during Round 2 to be ranked:

- Timely Buyout - locking in prices with contracts or purchase orders immediately following bid acceptance, in order to keep the price constant for the duration of a project.

- Contract Language - Price fluctuation language or clauses in contracts that clarify who has the risk for potential price fluctuation and/or how it will be handled. 
- Inventory Management - Purchasing large quantities of materials at a certain price and storing them until needed.

- Bid Expiration Dates - Stipulating the amount of time a bid is good for. For example, "this bid is good for____ days".

- Relationships - Maintaining good relationships and regular communication regarding current pricing with subs and suppliers in order to better anticipate price fluctuation.

Overall, the panel ranked "relationships" as the most effective method, with an average ranking of 2.45. "bid expiration dates” followed closely with an average rating of 2.49, and “contract canguage” was behind that with 2.87. In $4^{\text {th }}$ place of the five options was "timely buyout” with an average ranking of 3.10. And receiving the overall lowest ranking with an average of 4.10 was “inventory management”.

The data collected during Rounds 1 and 2 was also collated to enable comparisons between the various players in the residential construction industry. According to the data, each of the involved parties had different levels of use for the various methods listed above. Additionally, each of the involved parties had different opinions of the effectiveness of the top five methods. Each party's response count from Round 1, and a description of the rankings assigned each practice listed above as received in Round 2 are included below.

General Contractor. These panel members’ responses showed the most even spread between the options during Round 1 . Of the total 16 responses given by general contractors, 4 responses (25\%) fell into the "contract language” category, and another 4 in the "relationships with subs/suppliers” category. “Timely buyout of contracts” and "inventory management” followed with 3 responses each (19\%). Finally "bid increases” and “accelerated schedule” received 1 response each (6\%). See the following figure: 
Table 4-10: General contractors' responses per price fluctuation method

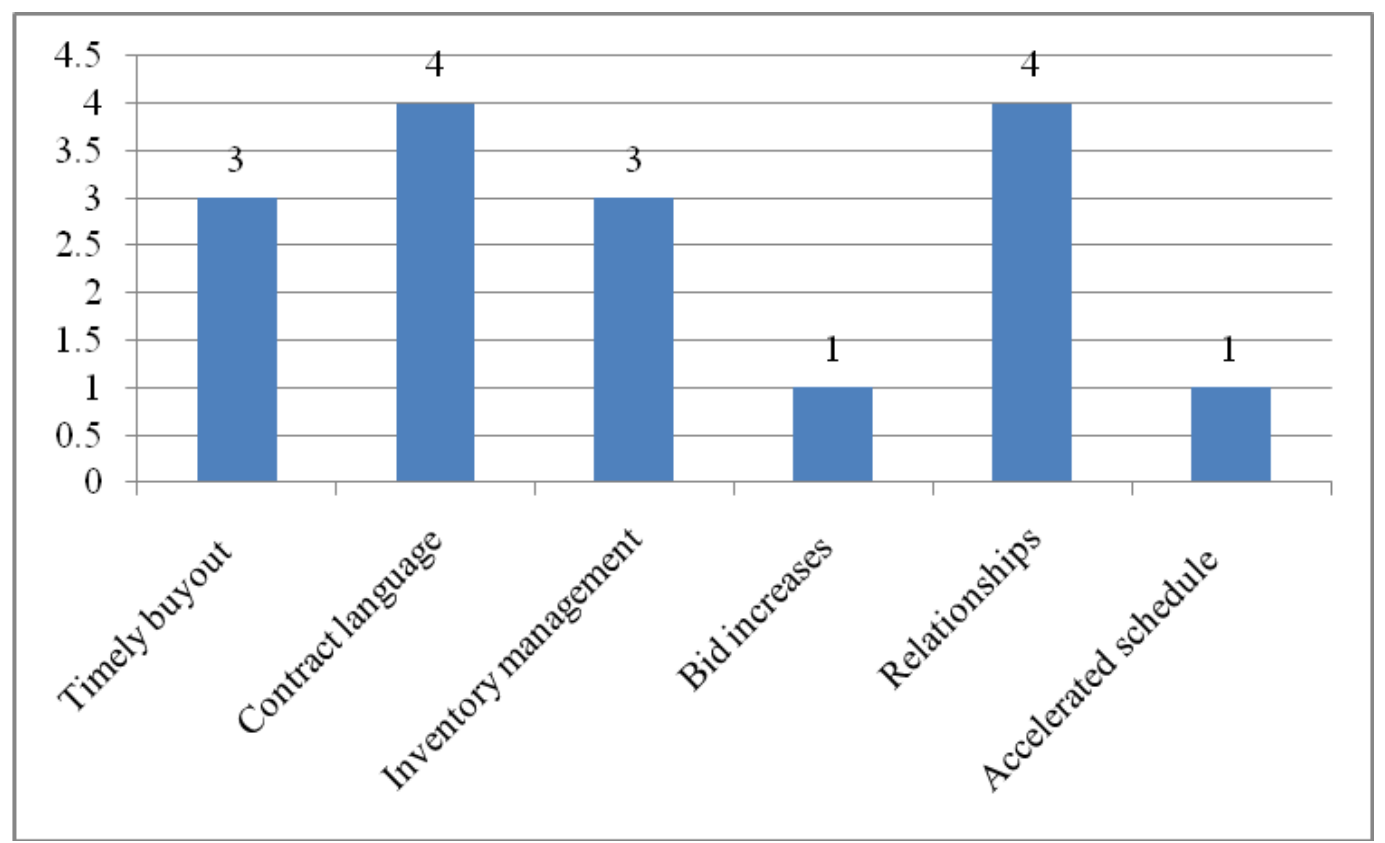

When asked in round 2 to rank the top five methods, general contractor panel members were basically in line with the overall rankings the panel as a whole had given. They ranked "relationships" as the most effective practice for managing the risk of price fluctuation. In a 3way tie for second place were "timely buyout", "contract language”, and "bid expiration dates", each with an average ranking of 2.86. Being viewed as the least effective of the methods was "inventory management", with an average ranking of 4.29 by the general contractors on the panel.

In order to further clarify current practices in use by the general contractors on the panel, additional questions were asked during round 2 about specific contract language used. Responses were divided into contract language used between the general contractor and the owner, the general and their subcontractors, and between the general and suppliers to allow for 
potential differences in wording and risk allocation. Included below are some of the responses received from the general contractors who were willing to share their contract language:

\section{Contracts with owners}

- If owner is not financed, or the home doesn't start within 90 days of contract signage, then estimate is null and void.

- Price escalation clause - if prices increase by $15 \%$ or more, general contractor will be unable to absorb additional costs, they will be passed on to the owner.

- Owner shall pay all costs due to rising material costs, if greater than $5 \%$.

\section{Contracts with subcontractors}

- The acceptance of this contract relieves the general contractor of the risk of potential price fluctuation.

- There is no specific language in our subcontract relative to price increases. The language does state that the only increases to the contract are to be pre-approved by [the general contractor] so if a trade did try to come back with a material cost increase, we could in theory deny the change order and maintain the price that was set during buyout. Our Letter of Intent does instruct the trade to begin acquiring materials or goods, dependent upon the particular trade’s schedule.

- Subcontractor will guarantee the price of all materials and labor if the job is to be started within a thirty day timeframe.

\section{Contracts with suppliers}

- The material bid will be good for the duration of any job started within thirty days from the bid date. 
General contractors were also asked to share what materials they stockpiled to protect against potential price fluctuation, if any. The following are the responses received:

- Lumber.

- We used to stockpile OSB for framing and aluminum siding. Now we don’t have the cash flow to stockpile anything.

- At different times we have stockpiled commonly used rebar in large quantities but have found that the cost of storage and handling, the risk of damage/ theft/etc. reduce the benefit of stockpiling. These days we are not stockpiling any material.

- 50 year silicone and window flashing.

When asked how they determine the volume or amount of material they will maintain in inventory, general contractors on the panel gave the following responses:

- Just based on what is in the pipeline, and how cheap prices are when buying.

- If we do purchase something because a supplier or trade has warned us of a cost increase, we only get enough for a specific job. Or, in the event that the financial institution only allows a certain dollar amount for a deposit, we max out that limit and hope for the best on the balance of the order.

- Based on what I see coming up.

Panel members were also asked in round 2 to share how long their bids are good for, on average. Responses from the general contractors ranged from 21 days to 360 days. One respondent reported his practice of having bids good for the remainder of the calendar year in which they were given. All general contractors reported that they do accept time stipulations from the people that they contract with. 
Subcontractors. Panel members in the subcontractor category gave the fewest responses to this question. Of the total 13 responses given by subcontractors, 5 responses (38\%) related to “inventory management” making it the most commonly reported method. "Timely buyout of contracts” was next with 4 responses (31\%). "Relationships with subs/suppliers” constituted 2 responses (15\%), followed by "bid increases” and “contract language” with 1 response each (8\%). Receiving no responses from sub-contractors was the "accelerated schedule” category.

See the following figure:

Table 4-11: Subcontractor responses per price fluctuation method

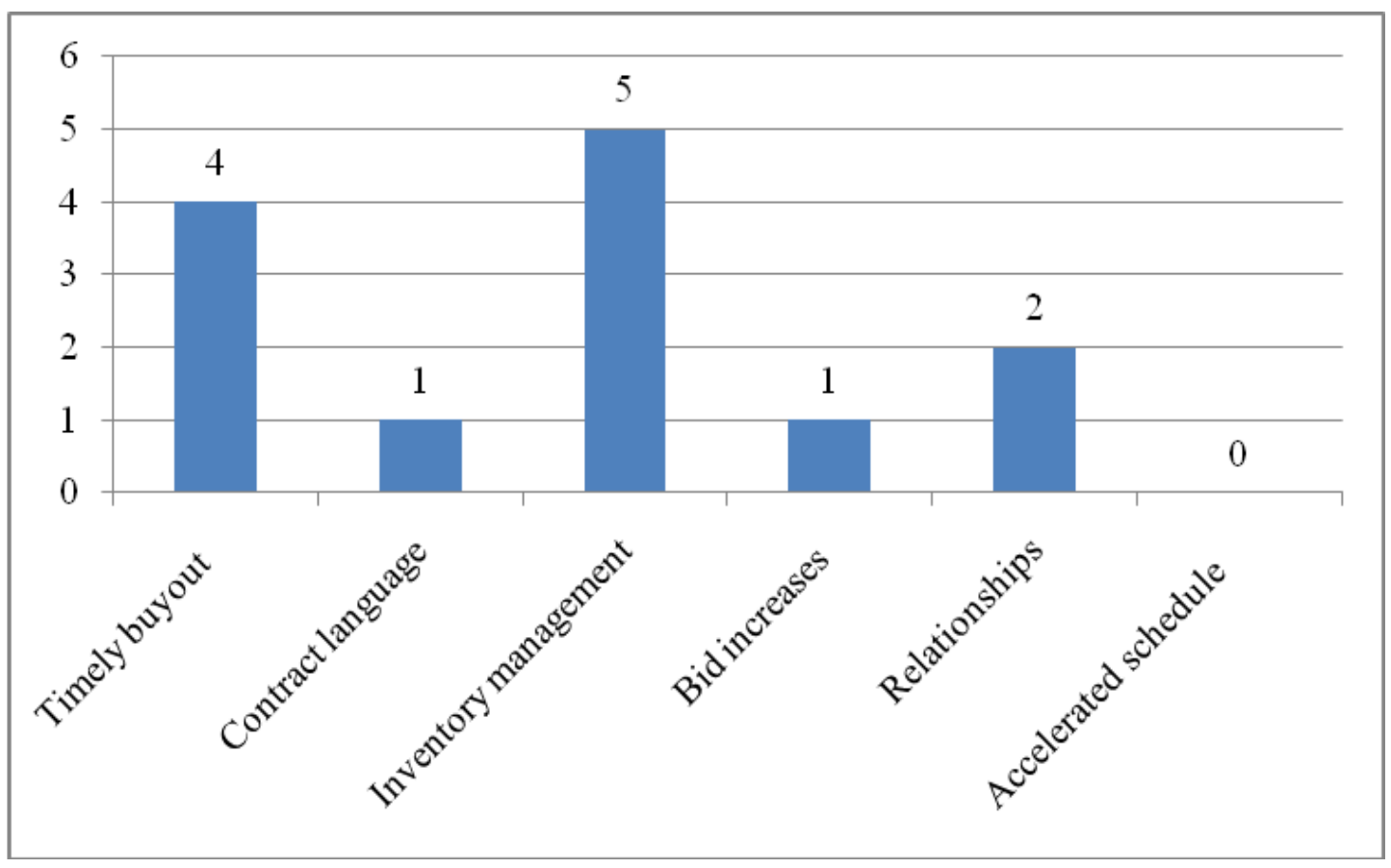

When asked to rank the top five methods, subcontractor panel member responses showed the smallest range of the three respondent categories. There was not a consensus $1^{\text {st }}$ place ranking as 3 of the practices received average rankings of 2.60. "Timely buyout”, “contract language", and "bid expiration dates" received this average ranking. Following these three 
practices was "relationships" with an average ranking of 3.20, and then "inventory management" with a 4.00. The subcontractor category was the only respondent category not to rank "relationships" highest among the available options.

In order to further clarify current practices in use by the sub-contractors, the same questions asked to the general contractors were asked during round 2 to the sub-contractors. Responses regarding specific contract language used to minimize the risk of price fluctuation were divided into the language used between the sub-contractor and the general contractor, the subcontractor and other subcontractors, and between the subcontractor and their suppliers. The only category that received responses was between the subcontractor and the general contractor. Included below are the responses received from the subcontractor panel members who were willing to share their contract language:

\section{Contracts with general contractors}

- Specified the number of days a bid is good, although changing that bid after 30days usually causes issues.

- Does not apply much in my business once contract is signed.

Subcontractors were also asked to share what materials they stockpiled to protect against potential price fluctuation, if any. The following are the responses received:

- Cable (wire).

- Granite.

- We stock our main products (popular colors, sealers, etc) but no incidentals (paper, tape, plastic, etc).

- None at the present time. 
When asked how they determine the volume or amount of material they will maintain in inventory, subcontractors on the panel gave the following responses:

- Enough for 2 average projects.

- We order on an as-needed basis.

- We make specific purchases upon acceptance of bid and deposit receipt, then store until needed. Also purchase general rolling stock in bulk when we find a bargain.

- Our salesmen communicate on the upcoming jobs that have signed bids, larger contractors issue PO's or schedules we can go by. Materials are standard in many cases -special orders are assigned and charged to specific jobs (no extras).

- Inventory is based on jobs in process.

Panel members were also asked in round 2 to share how long their bids are good for, on average. All 5 subcontractor panel members responded that their bids on residential projects were typically good for 30 days. All subcontractors also reported that they do accept time stipulations from the people that they contract with.

Supplier. A total of 17 responses were received from panel members in the supplier category. Predictably, the method most utilized by suppliers to manage the risk of price fluctuation was "inventory management” with 8 responses (47\%). Dropping substantially from there to 4 responses (24\%) was "contract language”. Receiving 2 responses each (12\%), the categories of "timely buyout" and "relationships with subs/suppliers" were the next highest. "bid increases” followed with 1 response (6\%) and "accelerated schedule” received no responses. See the following figure: 
Table 4-12: Supplier responses per price fluctuation method

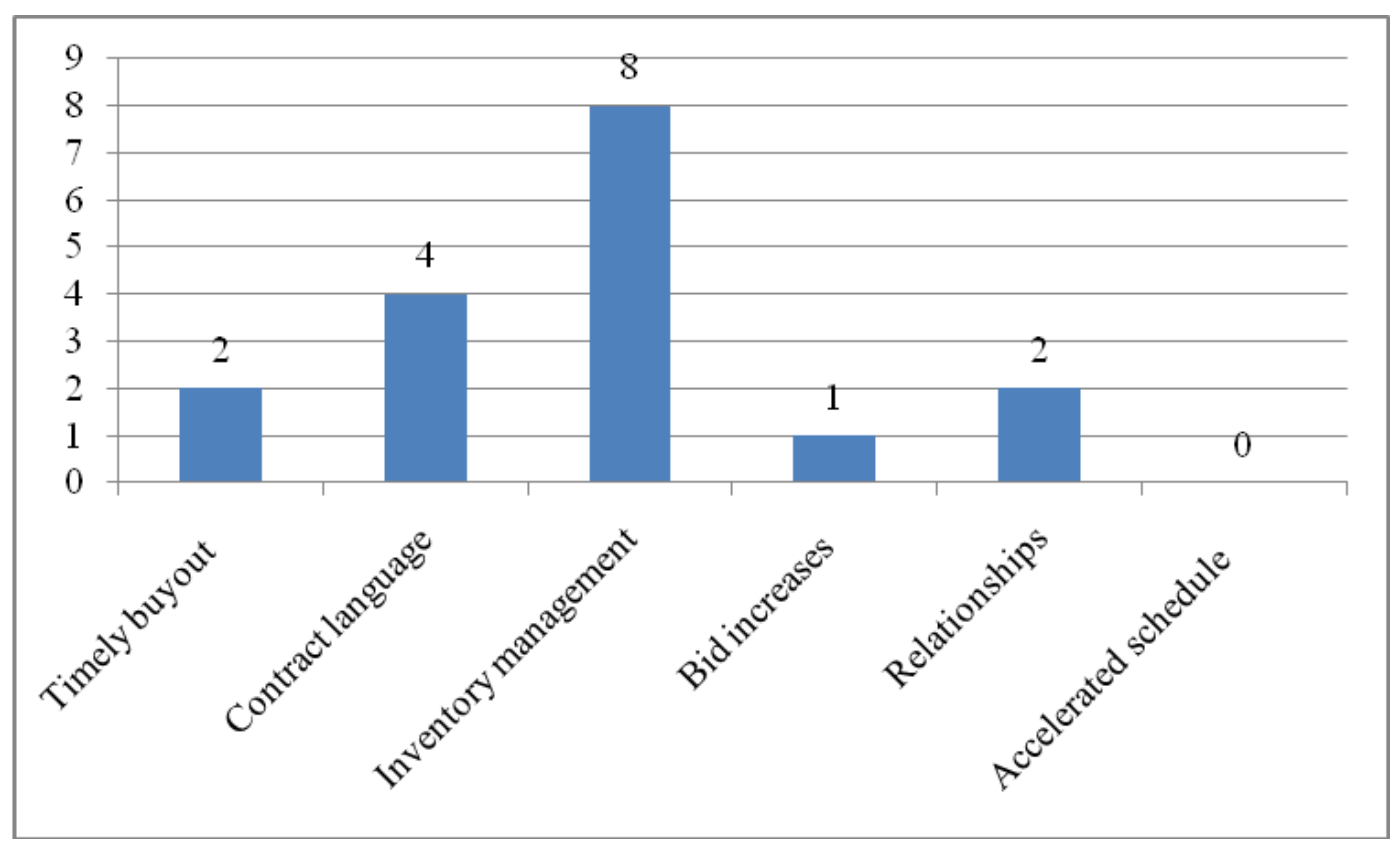

When asked to rank the top five methods, average supplier panel member responses showed some unexpected results. Despite being used far more regularly by the panel members in this respondent category, "inventory management" received the lowest overall ranking of the 5 available practices listed, coming in at 4.00. Tied for the highest ranking were "bid expiration date" and "relationships" with average rankings of 2.00. This is also interesting when it is noted that during round 1 of the questionnaires, supplier panel members only reported "relationships" as a method utilized twice out of 17 responses. "contract language" came in at 3.17, and "timely buyout” ended up with 3.83 .

Like the general contractor and subcontractor categories above, supplier panel members were asked additional questions during round 2 in order to further clarify current practices in relation to specific contract language used. Responses were divided into contract language used between the supplier and the general contractor, the supplier and subcontractors, and between the 
supplier and other suppliers. Included below are some of the responses in each of those categories, as received from the suppliers who were willing to share their contract language:

\section{Contracts with general contractors}

- Each contractor has their own contract, usually according to size of job. Some just order on their accounts, others have lengthy legal contracts that often times have to be redlined. They usually just protect themselves in these contracts.

- Bid good for days.

$\underline{\text { Contracts with sub-contractors }}$

- We pay upon receipt of work or materials finished unless deposits are required.

Contracts with other suppliers

- All quotes are valid for 30 days unless otherwise noted. Some material volatility may warrant special considerations in and will be noted as such.

- Our material suppliers are bound to keep fixed pricing for a minimum of 30 days.

Supplier panel members were also asked to share what materials they stockpiled to protect against potential price fluctuation, if any. The following are the responses received:

- Materials used in regular production, usually non-risk if job is cancelled and materials are used on other similar jobs. Sugar in the bin was how old timers called it.

- $\quad 7 / 16$ 's OSB and studs.

- I do not stockpile material.

- High volume items- studs and OSB.

- Tile, stone, and product setting materials.

When asked how they determine the volume or amount of material they will maintain in inventory, suppliers on the panel gave the following responses: 
- Regular moving inventory. If material is stored at a supplier that is close and has the same price with short lead times, we let them carry the burden. We used to have a larger inventory with quicker service, but now wait for weekly deliveries.

- According to prices from manufacturer.

- We have an industry sensitive computer program that allows us to review the past 13 month's usage and makes a calculated suggestion for purchasing. It can be easily overridden if desired but the program recommendations are pretty accurate. I try to store no more than a month's worth of sales unless I am required to buy in standard packages. I try to purchase in quantities that are freight allowed.

- Prior History usage and forecast from sales team

Panel members were also asked in round 2 to share how long their bids are good for, on average. Responses from the suppliers ranged from 7 days to 6 months. Included below are a couple of responses that contained additional interesting information in response to this question:

- 30 days...but the reality is that most bids are honored unless there are major changes in costs.

- Bids are good for 6 months except for natural stone which is only good for 3 months due to the fluctuation of the dollar on the international market.

All suppliers surveyed reported that they do accept time stipulations from the people that they contract with.

\subsection{Risk Allocation of the Various Contracting Methods}

The various contracting methods allocate or divide the risks associated with construction amongst those involved in the process. Three of the questions included in round 1 of the 
research were devised to ascertain how effective panel members found the various methods to be at spreading the risk of price fluctuation. Panel members were asked to assign the level of risk they feel is currently placed on each party for the various contracting methods. Additionally, they were asked to assign the level of risk they feel should be placed on each party. The difference in these answers reveals the panel's overall disposition regarding the current system. Panel members in each category were also asked to rate the various methods as to their ability to spread or share the risk of price fluctuation using a 1-5 scale where 5 is extremely equitably, and 1 is extremely inequitably. On average, the panel as a whole rated cost plus contracts highest on this scale with a score of 4.03. Also, despite being the most used overall, fixed price contract's average score was 3.28 placing it in $3^{\text {rd }}$ out of the 4 contracting methods. See the table below:

Table 4-13: Average overall equitability rankings by contracting method

\begin{tabular}{|c|c|c|c|c|}
\hline \multirow{2}{*}{4.50} & \multirow{2}{*}{\multicolumn{2}{|c|}{4.03}} & \multirow{4}{*}{3.56} & \multirow[b]{5}{*}{2.92} \\
\hline & & & & \\
\hline 4.00 & \multirow[b]{2}{*}{3.28} & & & \\
\hline 3.50 & & & & \\
\hline 3.00 & & & & \\
\hline 2.50 & & & & \\
\hline 2.00 & & & & \\
\hline 1.50 & & & & \\
\hline 1.00 & & & & \\
\hline 0.50 & & & & \\
\hline \multirow[t]{2}{*}{0.00} & & & & \\
\hline & Fixed Price & Cost Plus & Unit Price & GMP \\
\hline
\end{tabular}

Responses to all three questions have been further segmented by respondent category to allow for additional data comparison. 
General Contractors. On average, panel members in the general contractor category reported that they themselves carried the majority of the risk in both fixed price and unit price contracts. Owners were viewed as carrying the majority of the risk in cost-plus and GMP type contracts. When asked how they would like to see the risk spread between the parties, for every type of contract except unit price, general contractors reported that they would prefer to see owners accepting more risk than they currently are. Two of the seven panel members in this category reported that current risk allocation the way that it should be. The following figure shows the averages in each category for the general contractors on the panel.

\section{Table 4-14: General contractors' average current and desired risk allocation to each party for each type of contracting method}

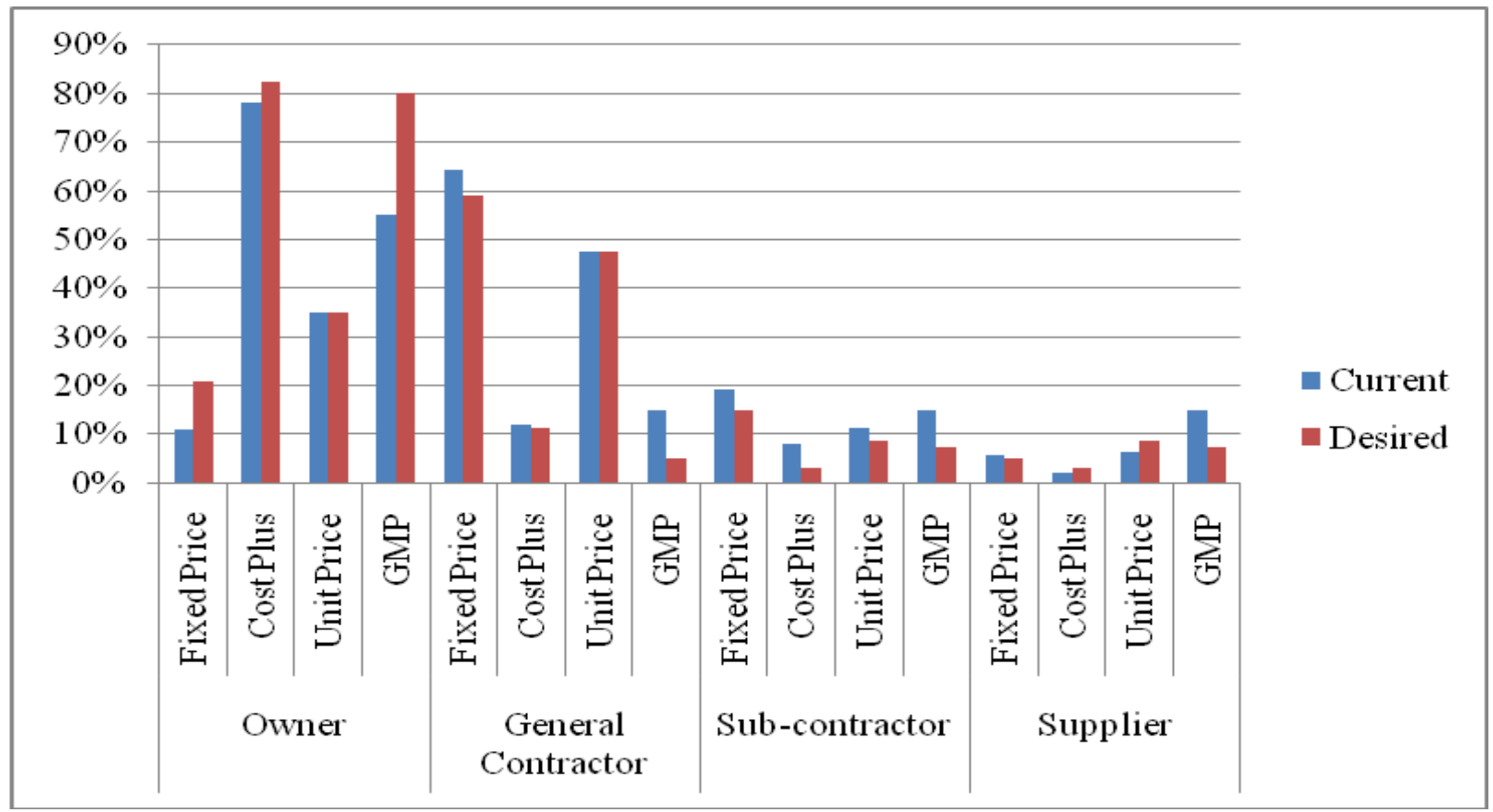

When the general contractors on the panel were asked to rate the various contracting methods as to their ability to equitably spread or share the risk of price fluctuation, most 
respondents rated cost plus highest amongst the options. Out of 5, cost plus received an average rating of 4.67, followed by unit price contracts with 4.17. Fixed price and GMP contracts both received average ratings of 4.00 . See the figure below:

Table 4-15: General contractor panel member's average equitability rankings by contracting method

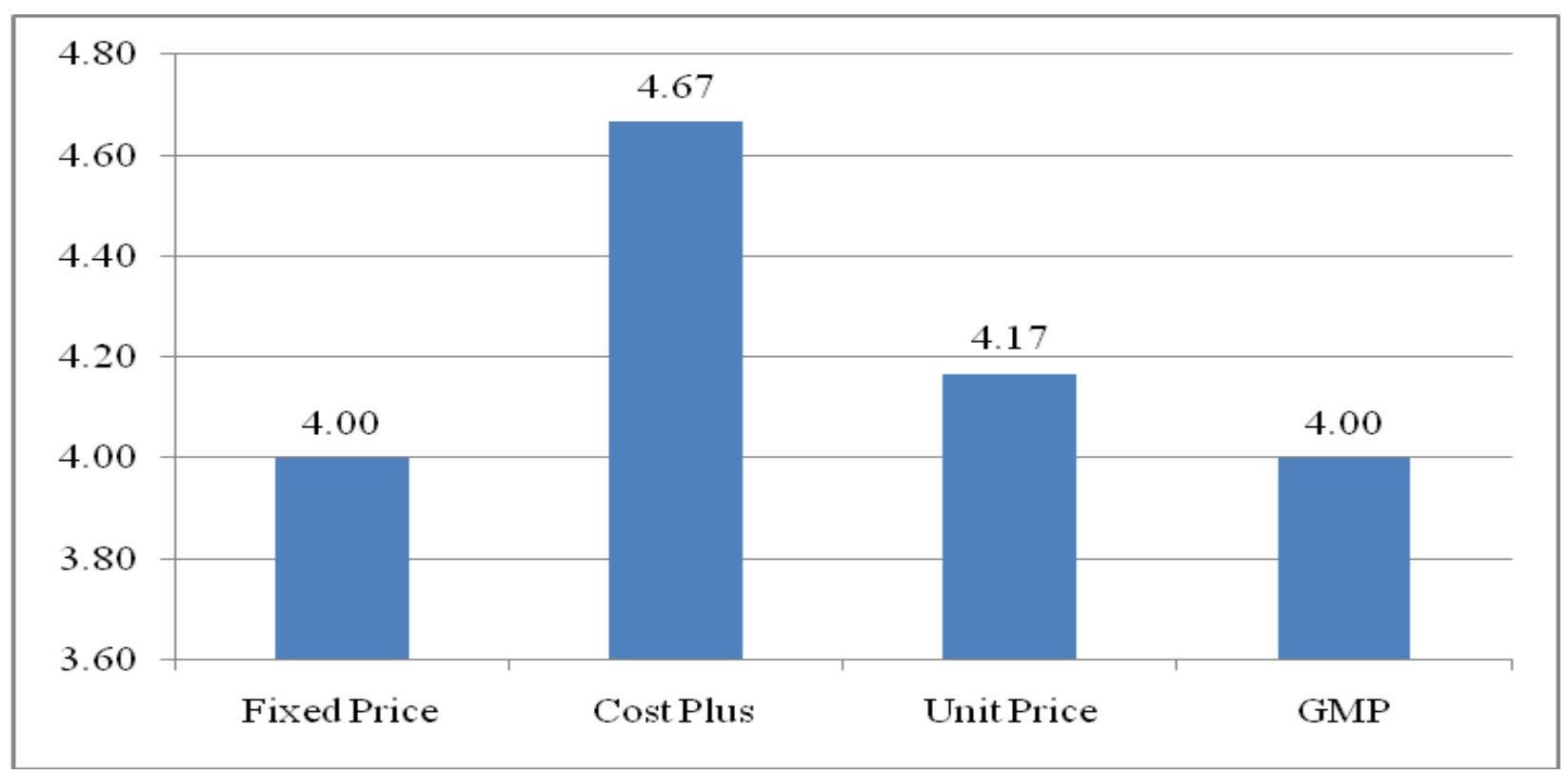

Subcontractors. Panel members from the sub-contractor category perceived the placement of risk quite differently than the general contractors. According to the data, subcontractors felt that they themselves carried the majority of the risk in 3 of the 4 types of the contracts. The exception is cost plus contracts where panel members viewed $95 \%$ of the risk as being carried by the owners. Two of the six subcontractors reported the same numbers in both questions, implying that current risk allocation is appropriate from their perspective. See the figure below: 
Table 4-16: Subcontractors' average current and desired risk allocation to each party for each type of contracting method

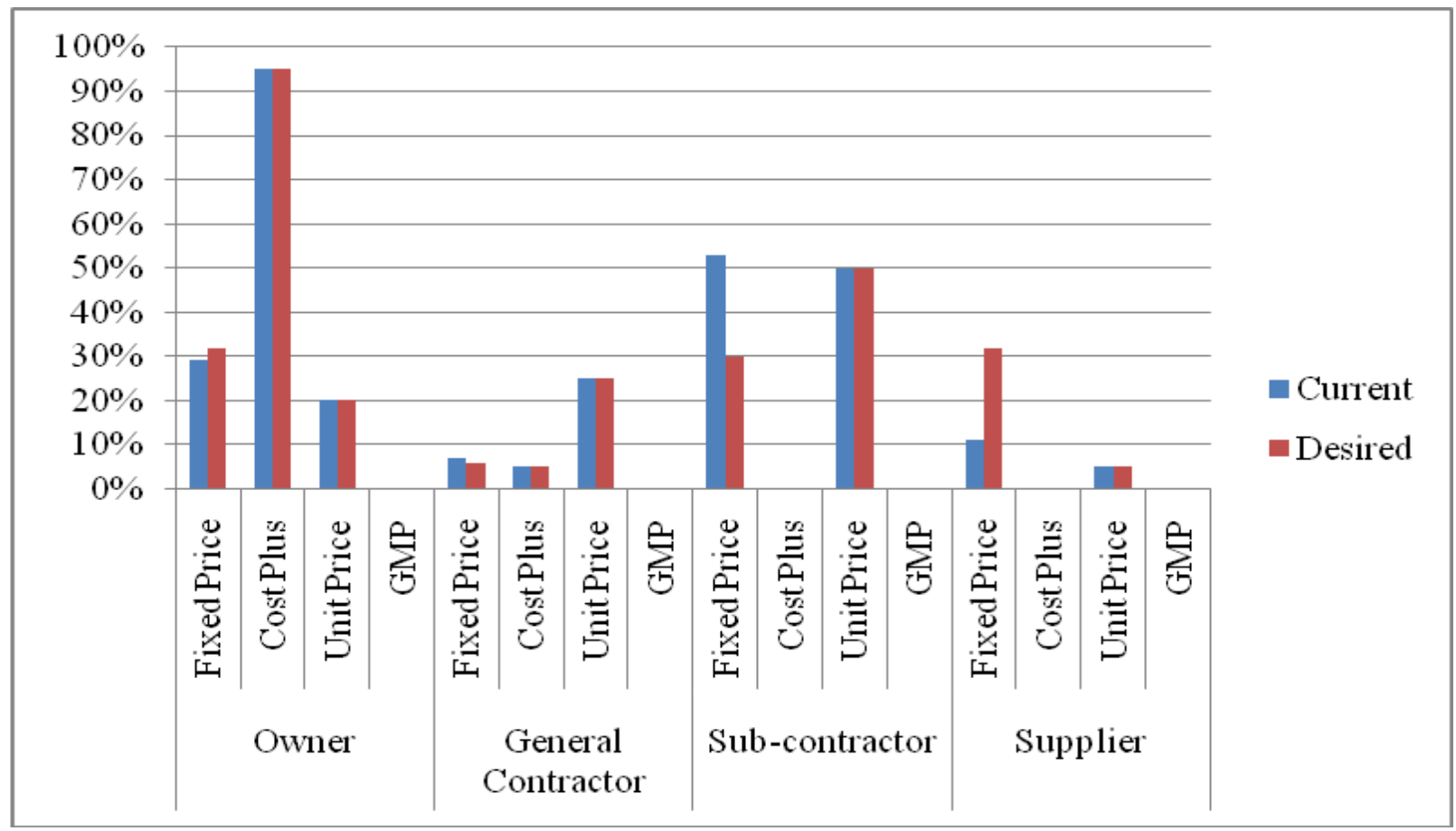

Subcontractors on the panel were also asked to rate the various contracting methods as to their ability to equitably spread or share the risk of price fluctuation. Like the general contractor category, sub-contractors rated cost plus contracts as the most equitable method of contracting. Cost plus received an average rating of 3.60. Unit price was next with 3.33 and fixed price contract's average raging was 3.17. Sub-contractors rated GMP contracts as the least equitable with an average rating of 1.75 . Overall, the average of all the scores given by sub-contractors was lower than both general contractors and suppliers, possibly indicating that this category of the panel feels that regardless of the contracting method, they are treated the most inequitably. See the figure below: 
Table 4-17: Subcontractor panel members' average equitability rankings by contracting method

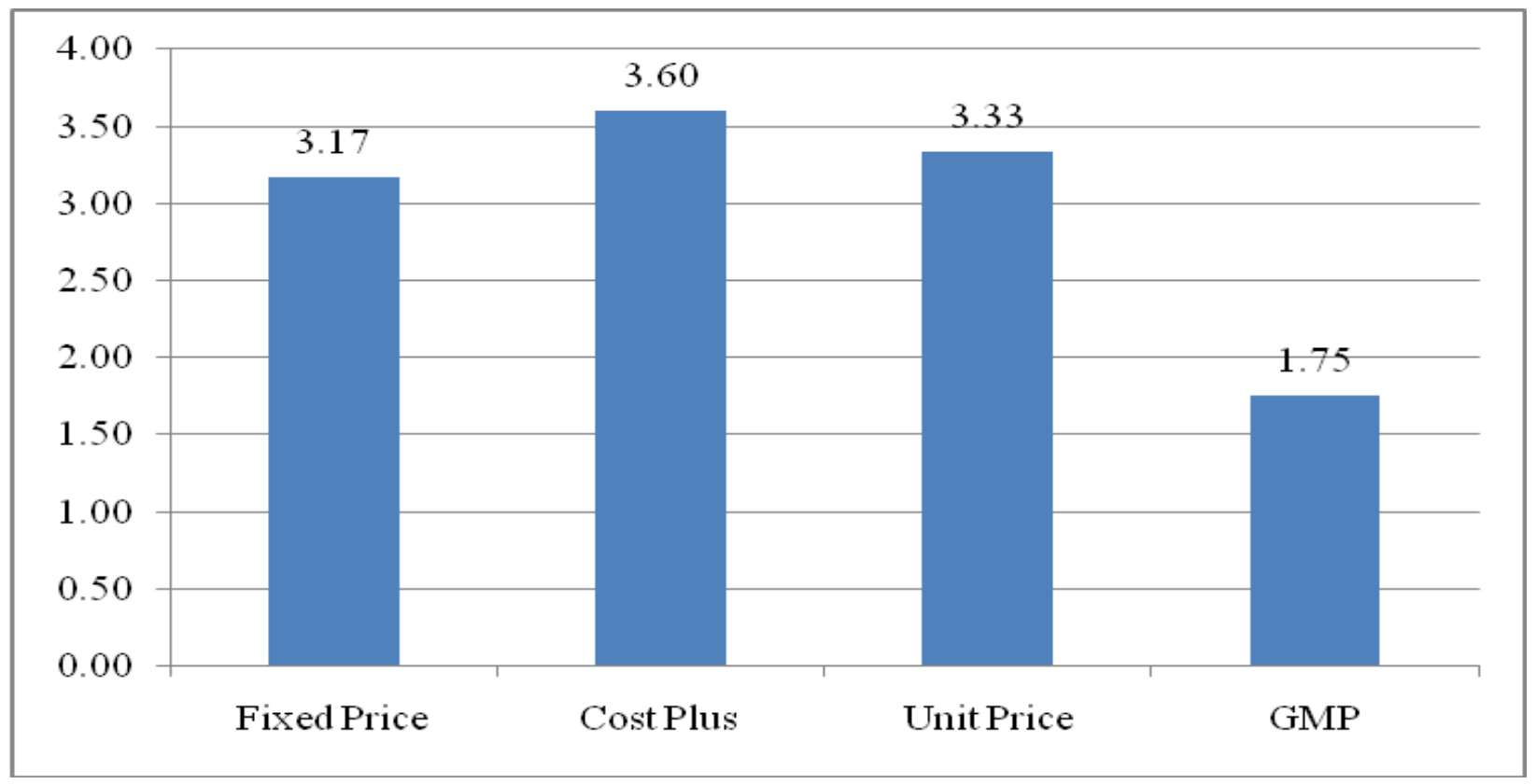

Supplier. Suppliers reported that the majority of the risk should be shared by the owners and the general contractors. Current perception is that owners have very little risk regardless of the contracting method. One of the six suppliers reported that the current risk allocations were the same as they thought that they should be. See the figure below for additional results: 
Table 4-18: Suppliers' average current and desired risk allocation to each party for each type of contracting method

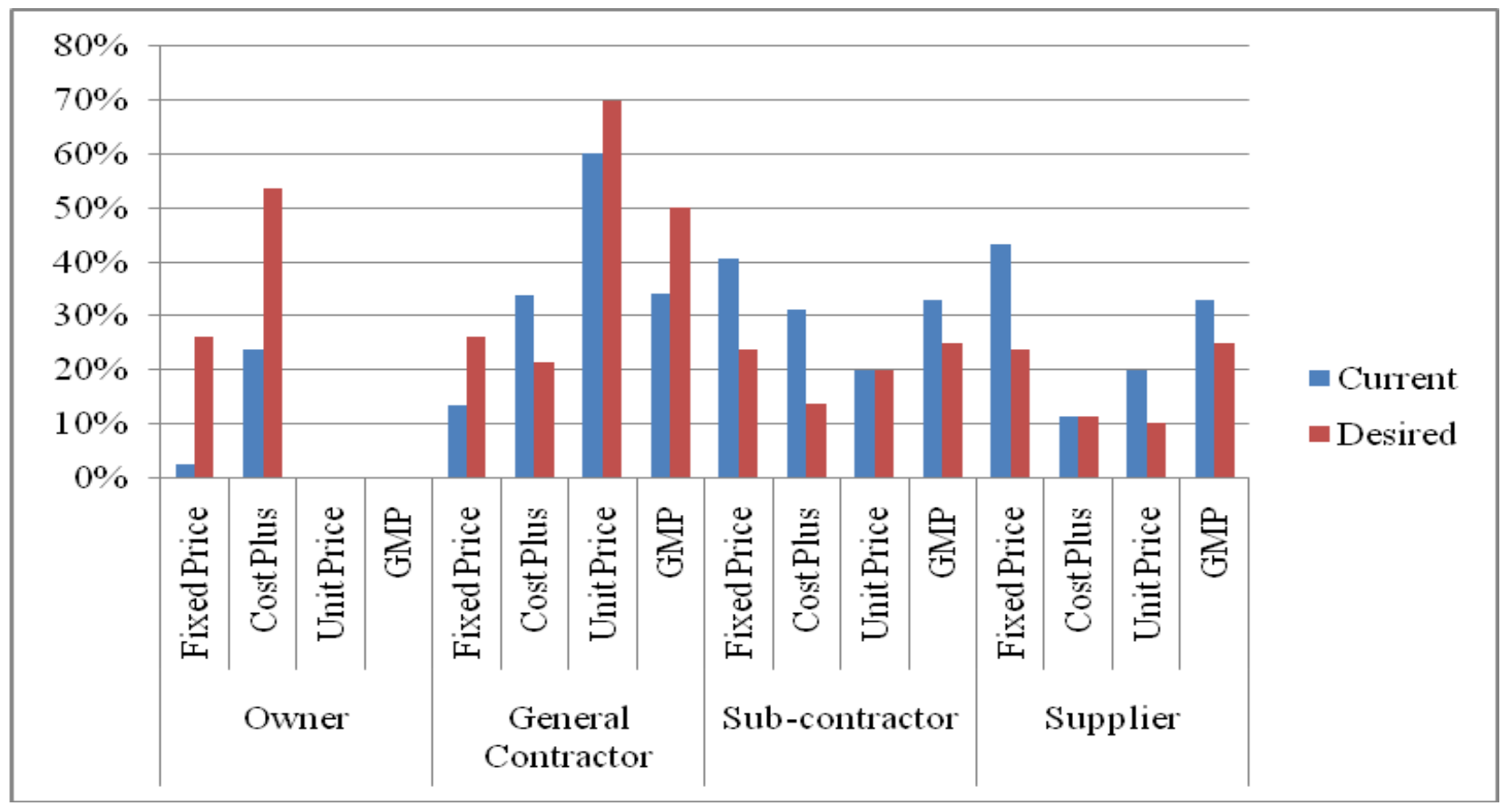

Suppliers on the panel were also asked to rate the various contracting methods as to their ability to equitably spread or share the risk of price fluctuation. Like the general contractor and sub-contractor categories, supplier panel members gave cost plus contracts the highest overall scores. Cost plus received an average rating of 3.83. Unit price was next with 3.17, followed by GMP with 3.00. The lowest scoring of the contracting methods was fixed price at 2.67. See the table below: 
Table 4-19: Supplier panel members' average equitability rankings by contracting method

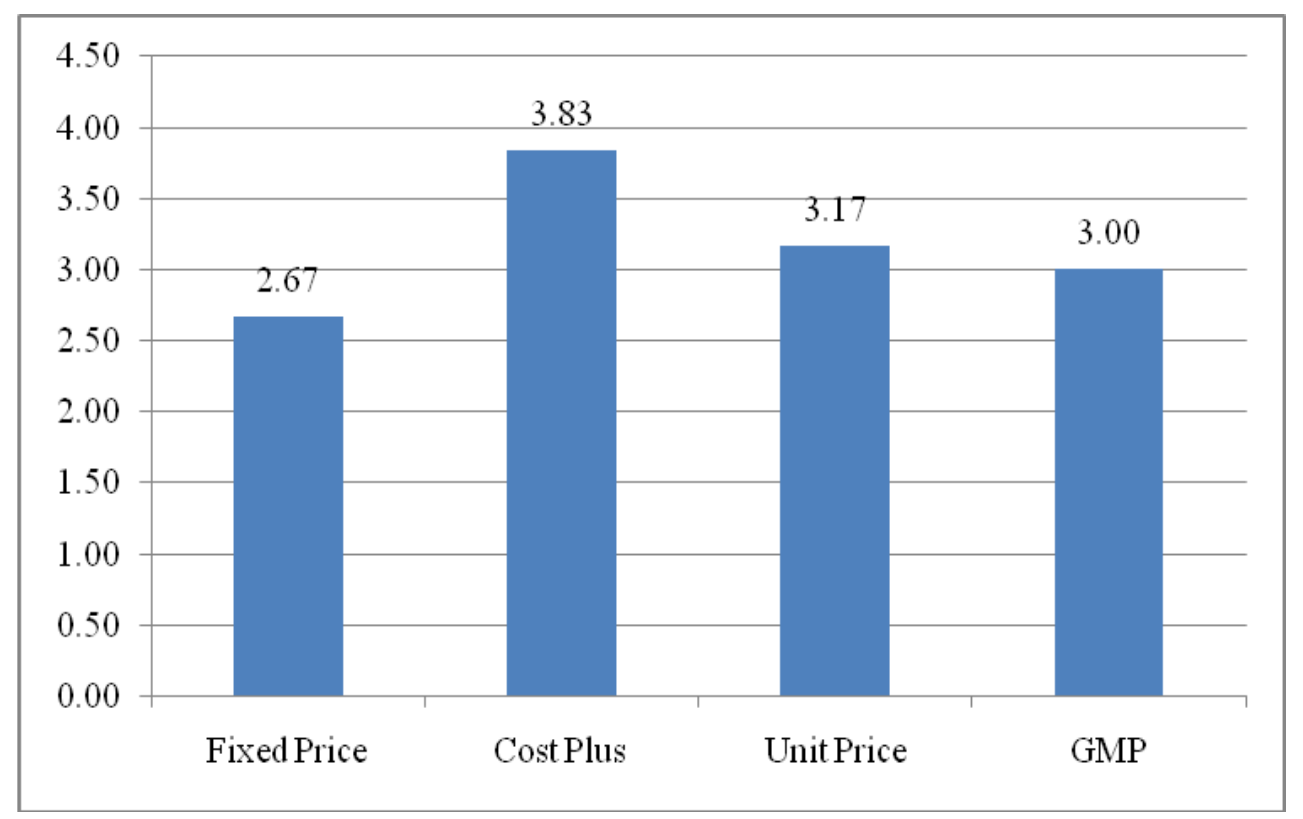

\subsection{Decreasing Price Issues}

The final question given to respondents during round 1 was open-ended and requested any thoughts that panel members had with regards to material, labor, or equipment prices decreasing in the market place. Panel members were asked to explain what problems, if any, they face when prices drop. The three most common answers have been categorized and listed below. Included under each category are examples of actual panel member responses.

1. No problems created, only benefits - 5 of 19 responses (26\%)

- Lower prices means demand for new units should increase, help stimulate desire for new homes.

- Haven't had any problems, would just work with people to be honest and fair.

2. Market competition increases. This often results in a decline in the quality of materials and/or labor being provided by the industry - 4 of 19 responses (21\%) 
- Quality of workmanship among builders and tradesmen drops. Hard to stay competitive as estimates are all over the place, resulting from too many unqualified builders that should not be building, even though demand is allowing it.

- Unqualified competition increases which results in poor construction quality, makes our industry look bad.

3. Companies are forced to take a loss on previous purchases in order to move material or product -3 of 19 responses (16\%)

- Losses on our end, have to ride the rollercoaster back down to stay competitive. Taking losses and trying to blow product out the door as soon as possible so that replacement product is coming in a cheaper price.

- Potential for getting stuck with higher priced copper that we've paid for in advance. Our inventory doesn't generally reflect decreases very quickly, so it can take time to average out.

The remaining responses did not fall into any of these three generalized categories. However, some of those additional comments have been included below for reference. The responses are as follows:

- The biggest problem was when the economy went south, everyone was rebidding jobs to get lower prices, but most manufacturer and supplier prices didn't change, so we ended up having to give discounts.

- General Contractors that bid the projects make excessive profit.

- Set overhead creates problems, can't sustain companies. 
- I've been in homebuilding since 1973 - never have seen it. If it did ever happen the government would find a way to tax it. If prices do fall and I can lower my sales price, all my previous buyers are unhappy! I can't win!!

- Shortages are created as people scurry to buy up the reduced priced items. This false demand can also push the prices back up. On cost plus jobs where a GC is tacking on a fixed fee, the multiplier goes down and ultimately leads to tighter margins if the reduction is of a sufficiently large nature. 


\section{CONCLUSIONS AND RECOMMENDATIONS}

\subsection{Best Practices}

As evidenced by the literature review, and the results of the Round 1 questionnaire, there are a variety of methods available for managing the risks of price fluctuation inherent to the residential construction industry. Because there are so many different potential causes of price fluctuation, it is extremely difficult to accurately predict upcoming changes in many critical construction costs. Each of the parties involved in the construction process are subject to this risk. As such, each of the parties must implement and utilize different tools and practices to attempt to mitigate their exposure to this risk, and protect themselves and their companies from the potentially disastrous effects of dramatic increases or decreases in prices during the course of any given project. The research of this study has shown that not only do the various methods have differing degrees of use within Utah’s residential construction industry, but they also have differing degrees of effectiveness as perceived by the parties involved. Each method is designed to allocate risk amongst the parties, and typically the party with the most negotiating power is able to determine how the risk is spread. This power is usually evident in the type of contract that ultimately is entered into between the involved parties. However, as was also shown by the research, there are practices available to each party that allow for increased protection from the risk of price fluctuation, regardless of the contracting method being utilized. 
Not surprisingly, the panel did not achieve $100 \%$ consensus on any single "best practice". However, the utilization of the Delphi method did allow for attainment of what can be considered the 5 best practices currently in use by the panel of experts. This section reviews and further analyzes these top five practices. They are included below in order of their overall ranking by the entire panel, as reported in Chapter 4 .

\subsubsection{Relationships}

The practice receiving the highest overall ranking from the panel members in its ability to manage the risk associated with price fluctuation was entitled "Relationships". As confirmed by the panel, implementation of this practice basically implies maintaining good relationships and regular communication with subs and suppliers. Respondents mentioned recommendations such as always paying sub-contractors and suppliers on time, and avoiding adversarial relationships with those you contract with, as ways to maintain positive relationships. Also, it was recommended that regular communication regarding potential price changes on volatile items occur to prevent unanticipated surprises. It has been the experience of the panel members that when relationships are strong and mutually beneficial to the parties involved, potentially damaging price fluctuation can be effectively, fairly, and appropriately shared and managed. One panel member reported that the reality of the situation is that when one party of the construction industry fails in a transaction, everyone involved loses. Litigation and damage costs incurred when parties fail to communicate and coordinate with each other continue to force higher costs of doing business, resulting in higher overall costs for everyone involved. Insurance premiums expand and profit margins shrink as parties in the construction project focus on protecting themselves at the expense of others involved. If difficulties resulting from price 
fluctuation could be approached with a primary focus on the relationships involved, solutions that are more equitable, and more conducive to business longevity, would result.

The difficulty with utilizing relationships as the primary defense against the risk of price fluctuation is that there are no guarantees. Court rulings are not typically made based on the status of two parties' relationship. There is nothing in writing and if things really took a turn for the worst, the parties would have nothing to fall back on. So, while good relationships and communication are considered the best way to manage the majority of the problems relating to price fluctuation, they should be supplemented by additional, agreed upon precautions in the form of other available practices.

\subsubsection{Bid Time Tables}

According to the research, another proven, practiced, and effective method for dealing with the risk of price fluctuation is the inclusion of bid time tables. Every panel member reported use of bid time tables as a regular practice for their business. Length of time tables received from respondents ranged from as short as 7 days, to as long as 1 year. The most common answer given by the panel regarding the period of time their bids are good for was 30 days. In reality, the risk of price fluctuation exists irrelevant of the amount of time a bid is good for. Naturally, the shorter the bid time table, the safer the bidding party should be from dramatic price increases or decreases. On the other hand, the longer the time table, the higher the possibility is that any one of the multitude of price impacting factors could force a change in the costs associated with a bid. This practice has obvious benefits and has proven to be reasonably effective at protecting the bidder from potential price fluctuation problems. 


\subsubsection{Contract Language}

Despite being one of the primary focuses of the research done in this area to date, contract language was viewed by the panel members as only the $3^{\text {rd }}$ most effective method for managing price fluctuation. Only 4 of the 19 panel members ranked "Contract Language" as the most effective method of the available options during Round 2. One panel member specifically stated, "Contracts are good for lawsuits, but relationships are good for business."

In practice, the inclusion of price adjustment clauses or other specific contract language was relatively rare among the panel members. One respondent went so far as to say that he actually purposefully avoided use of his adjustment clause when possible, even though he had one. It seems evident that the contract language currently being used in panel member contracts is perceived as either being ineffective, or as too expensive to attempt to fight for in court. Also, that the costs of litigation for most general contractors, sub-contractors, and suppliers to defend price adjustment clauses or other price fluctuation related contract language, is such that it poses a more precarious risk than price fluctuation itself.

\subsubsection{Timely Buyout}

The practice of locking in pricing with contracts or purchase orders immediately following bid acceptance was well used by the panel members. Early purchase of materials once contracts have been signed protects both sides of a contract because pricing can be guaranteed. However, "timely buyout" carries with it a variety of complications that lessen its effectiveness as perceived by the panel members. There are four primary problems that came up during phone interviews that can occur when a company practices "timely buyout" to avoid the risk of price fluctuation. 
1. Storage - The storage of pre-purchased materials carries additional costs with it. Also, it leaves materials at risk for possible theft and/or damage.

2. Financing - Pre-purchasing also necessitates money up front. One side of the agreement must essentially finance the purchase.

3. Project stoppage - In the recently all-too-common scenario where a project stops prior to completion, the early purchaser of a given product is likely to be stuck with it. It is possible that the pre-purchased material can be used on another job, but it is also possible that it cannot be used somewhere else.

4. Price decreases - In the relatively rare situation that prices actually decrease prior to installation of a pre-purchased material or item, the purchaser runs the risk of being stuck with uncompetitive higher priced product that may have to be sold at a loss.

\subsubsection{Inventory Management}

Receiving the overall lowest ranking of the five options was "inventory management". This practice is described as the purchase of large quantities of materials at certain price points and then storing them until needed. When prices are increasing, this gives the purchaser a distinct advantage over other competitive bidders who must purchase their materials at the higher prices. This can result in increased bid awards for the purchaser due to their ability to lower prices without affecting other margins.

This practice faces the same difficulties as those listed above under "timely buyout”. As mentioned, having a large amount of material on hand presents additional problems and risks to the purchaser of those materials. The party making the decision must way the benefits of having the potentially cheaper material with which to bid, against the risks mentioned above in order to make an informed decision. 


\subsection{Recommendations for the Industry}

Based on the results of the research conducted with the panel members involved in this study, recommendations have been produced for the professionals who work in Utah's residential construction industry. This section details those recommendations.

It is first and foremost recommended that the issue of price fluctuation be specifically explained and discussed between the involved parties during the initial stages of contracting and negotiations. Regardless of which parties are involved in the transaction, or which contracting method is selected, having both sides of the deal on the same page from the beginning allows for improved communication, and cooperation on the issue. Having an accepted and approved plan in place for dealing with price fluctuation allows for project players to work through and share potential costs. This team attitude is critical to the success of the project and needs to be embraced by everyone involved. This recommendation corresponds directly with the highest ranking practice as determined by the research. It was the opinion of the panel that focusing on the relationships involved in any part of the residential construction transaction is the best way to equally and appropriately share the risk of price fluctuation.

Also, due to the fact that the research did not arrive at one ultimately conclusive method that effectively and efficiently shares the risk of price fluctuation between all parties involved, it is recommended that the concerned party implement a combination of the best practices listed above. Reliance solely on any one particular method still leaves that party exposed to risk. No single method was proven to be $100 \%$ effective at protecting the practitioner from the risk of price fluctuation.

It is also recommended that the practice of bid time tables be complemented by the inclusion of a time table for scope of work to begin. All panel members reported use of a bid 
time table, but only a few reported use of an associated time table for work to begin. Depending on what other practices a company has in place to protect themselves from price fluctuation, use of a bid time table alone may still leave them exposed to some risk.

It is recommended that contract language specifically detailing or assigning the responsibility for the risk of price fluctuation be included in all contracts. On this same token, it is dually recommended that reliance on said contract language be avoided if at all possible, and that other means of sharing the risk be cultivated and coordinated between the involved parties. Contract language should be part of the deal from the beginning, but should be the last resort when problems arise.

\subsection{Recommendations for Additional Study}

The intent of this research study was to determine what practices for dealing with the risk of price fluctuation are currently in use in Utah's residential construction industry. Furthermore, the research solicited panel member opinions on the sufficiency of those practices. The research invited a broad view from a variety of parties currently doing business in Utah, both in size and in role within the industry. There are many peripheral pieces of this research that could benefit from further study and research in order to form additional conclusions and recommendations. The following are suggestions for additional research topics:

It is recommended that additional study be done to determine effectiveness of specific contract language currently in use and designed to protect against the risk of price fluctuation. This study requested examples of panel member contract language but did not have the resources to clarify and explore this area further. It is unclear how effective these examples would actually be when put to the test in court. 
Additional study into the effectiveness and results of material stockpiling could yield more specific recommendations for what materials have proven worth keeping on hand. Actual costs associated with stockpiling should be compared to average savings to determine how far this practice should be taken. This concept is applicable to a multitude of industries and warrants a closer look.

Since the "relationships" practice was the highest ranking method in this research, but is nevertheless relatively ambiguous, this area could definitely benefit from additional research. Specific practices that strengthen relationships between general contractor and sub-contractor, sub-contractor and supplier, owner and general contractor, etc., should be studied and described. What types of attributes and practices do general contractors have that would encourage subcontractors and suppliers to share the risks associated with construction with them? In an industry where relationships are critical to success but contracts are getting longer and longer, how should we act towards the other parties in order to be successful together? A concentrated study into the practices of those companies whose peers willingly accept some of the risks, in order to do business with them could provide recommendations for those striving to get there.

As evidenced by the literature review, conceptual cost estimation software/programs are becoming more prevalent and sought after in bigger construction firms throughout the country. Where high volume production occurs, minor changes in construction costs can lead to major impacts on profit. The use of this conceptual cost estimation software throughout the construction process could provide reliable benchmark indices that could be used to determine price adjustment clause execution or activation. A study into the effectiveness of this software at appropriately triggering price adjustment clauses is also recommended. 


\subsection{Implications}

The data and information collected in this research has provided specific practices for dealing with price fluctuation in use by general contractors, sub-contractors, and suppliers currently operating in Utah's residential construction market. Based on the analysis of this information, the following implications have been made.

With communication and transportation methods improving, local construction is increasingly becoming affected by the global market. The changes that have occurred and continue to occur in this arena allow for world-wide events to have an impact on pricing in Utah's market. Prices in Utah will continue to be at the mercy of uncontrollable factors around the world such as weather, catastrophes, and demand for global materials. Price fluctuation is a problem that will not go away, and as such, it is a risk that needs to be addressed by each party involved in the construction contract.

There is not a method that by itself protects the practitioner from all the risks associated with price fluctuation. Each method has both advantages and disadvantages, and can be appropriately used in certain situations. Where the factors creating this problem are so diverse, difficult to anticipate, and potentially uncontrollable, there is not likely to be one solution to this problem. Companies participating in the construction process must employ a variety of techniques depending on the specific risk that is at hand, and work with other parties in order to survive times of extreme price volatility. 


\section{REFERENCES}

Adler, M. and Ziglio, E. (1996). Gazing into the oracle: The Delphi Method and its application to social policy and public health. London: Jessica Kingsley Publishers.

Agapiou, A., Flanagan R., Norman G., and Notman D. "The changing role of builders merchants in the construction supply chain”. Construction Management and Economics 16, no. 31998). : 351-361.

Baccarini, D. The maturing concept of estimating project cost contingency-a review. (2006).

Barnes, N. M. L and Thompson, P. A., 1971. "Civil engineering bills of quantities”. CIRIA Report 34, England

Bashford, H. H., Sawhney A., Walsh K. D., and Kot K.. Implications of even flow production methodology for US housing industry. Journal of Construction Engineering and Management 129, 2003). : 330.

Bisbee, L. "Rising materials prices elevate construction costs". Wyoming Business Report (July 1, 2008) http://www.wyomingbusinessreport.com/article.asp/id=94871

Chan, E. H. W. and Au, M. C. Y.. "Factors influencing building contractors' pricing for timerelated risks in tenders." Journal of Construction Engineering and Management 135, no. 3 $(03,2009)$ : : 135-145.

Chen, D. and Hartman, F. T. "A neural network approach to risk assessment and contingency allocation. AACE International Transactions, (2000): 07.01-07.06

Choi, M., Kim, J., and Kim, M. "A study on the price escalation system in a construction contract.” KSCE Journal of Civil Engineering 10, no. 4 (07, 2006). : 227-232

Dalkey, N. C., Brown, BB, and Cochran, S. The delphi method. Santa Monica, CA: Rand Corporation1969.

Economic Development Committee for Building, 1974. Price adjustment formulae for building contracts, H.M.S.O, London.

Fayek, A, Ghoshal, I., and AbouRizk, S. "A survey of the bidding practices of canadian civil engineering construction contractors.” Canadian Journal of Civil Engineering 26, no. 1 (02, 1999). : 13-25. 
Fung, A. “Construction Costs Tumble in NYC”. Crain's New York Business.com. Published September 16 ${ }^{\text {th }}, 2009$ http://www.crainsnewyork.com/article/20090916/FREE/909169985

GNB. "Cross cutting management issues". GNB - Measures, Markers and Mileposts Washington State Department of Transportation. Published September 30, 2007 www.wsdot.wa.gov/biz/construction/GNB/3q2007graybook.pdf

Grogan, T. “Increased material price volatility.” ENR 231, (12/20, 1993). : 25-45.

Helmer, O., and Rescher, N. On the epistemology of the inexact sciences. Management Science 6, no. 1 (Oct., 1959). : 25-52.

Ichniowski, T. and Grogan, T. "Economics: Escalation eases but costs remain high.” ENR 258, no. $11(03 / 19,2007)$ : : 35-36.

Korman, R. “The art of negotiating price relief.” ENR 252, no. 26 (06/28, 2004). : 29-29.

Likert, R. A technique for the measurement of attitudes. Archives of Psychology.Vol 22, no. 1401932). : 55.

Ludwig, 1997 (pg. 2) Predicting the future: Have you considered using the Delphi methodology? Journal of extension, 35 (5), 1-4. Retrieved November 6, 2005 from http://www.joe.org/joe/1997october/tt1.html

Martino, J. (1983). Technological forecasting for decision making. 2nd ed., American Elsevier, New York

Matsumoto, A. "Let it be: Chaotic price instability can be beneficial." Chaos, Solitons \& Fractals 18, no. 4 (11, 2003). : 745-758.

McGoldrick, T. "Material price increases: What can you do?” The Chemical Engineer (no. 7862006).: 18

Moore, M. A. "Build local, price global”. California Consruction-McGraw Hill Construction (July 2008) http://california.construction.com/features/archive/0807_feature1.asp

Murray, M. A. "Construction contracting: The problem with competitive bidding." Materials Performance 32, $(08,1993)$ : : 34-36.

NAHB, 2010 National Association of Home Builders: Reshaping and Enriching Our Communities. Retrieved June $28^{\text {th }}$, 2010 from http://www.nahb.org/page.aspx/landing/sectionID $=5$ 
Nelson Sand \& Gravel, Inc. v. Ring, 2002-Ohio-6467, Ashtabula App. Nov. 22, 2002. Retrieved June $28^{\text {th }}$, 2010 from http://statecasefiles.justia.com.s3.amazonaws.com/documents/ohio/eleventh-district-courtof-appeals/2002-ohio-6467.pdf

Ng, F. P., Björnsson, H. C., and Chiu, S. S. "Valuing a price cap contract for material procurement as a real option.” Construction Management \& Economics 22, no. 2 (02, 2004). : 141-150.

Okpala, D. C. and Aniekwu, A. N. "Causes of high costs of construction in nigeria." Journal of Construction Engineering and Management 114, (06, 1988). : 233-244.

Picken, D. H. and Mak, S. Risk analysis in cost planning and its effect on efficiency in capital cost budgeting. Logistics Information Management 14, no. 5/62001). : 318-327.

PMI [Project Management Institute] (2004) A Guide to the Project Management Body of Knowledge. $3^{\text {rd }}$ Edition, Newtown Square: PMI.

Setzer, S. “Renegotiations make bad times worse.” ENR 262, no. 9 (03/23, 2009). : 33-33.

Smith, G. R. and Bohn, C. M. "Small to medium contractor contingency and assumption of risk." Journal of Construction Engineering and Management 125, no. 2 (March, 1999). : 101-108.

Terje, K. J. and Lereim, J. Management of project contingency and allowance. Cost Engineering 47, no. (2005). : 24-29.

Thompson, P. A. and Perry, J. G. Engineering construction risks: A guide to project risk analysis and risk management. 1992).

Tulacz, G. J. "The top 100 design-builders, construction managers for-fee, construction managers at-risk \& the top 40 project managers volatility leads to new thinking.” ENR 256, no. 23 (06/12, 2006). : 34-36.

Walsh, K. D., Bashford, H. H., and Sawhney, A. "Cost of risk transfer: Pricing agreements in residential supply chains.” Journal of Architectural Engineering 10, no. 3 (09, 2004). : 112118.

Waugh, F. V. Does the consumer benefit from price instability? The Quarterly Journal of Economics 58, no. 41944). : 602-614.

Williams, T. "Predicting changes in construction cost indexes using neural networks". Journal of Construction Engineering and Management 120, no. (1994).: 306

Yu, Wen-Der. "PIREM: A new model for conceptual cost estimation." Construction Management \& Economics 24, no. 3 (03, 2006). : 259-270. 


\section{APPENDIX A. SELECTED PANEL MEMBERS}

\section{General Contractors}

- Cade Harris, Owner - Timepiece Homes, Logan, UT

- Tom Braun, Owner - Braun Construction, Cedar City, UT

- Bryan Bird, Senior Project Manager - Magleby Companies, Lindon, UT

- Brandon Schank, Owner - Gateway Home Construction, Cedar City, UT

- John Aldous, President and COO - Hamlet Homes, Murray, UT

- Scott Jones, President - J2 Homes Inc, Orem, UT

- Adam Arrington, Owner - Arrington Development, St. George, UT

\section{Sub-Contractors}

- David Maples, Owner - Ambienti LLC, Park City, UT

- Curt Harrison, Owner - Rocky Mountain Custom Countertops, Murray, UT

- Steve Schmid, Owner - Stone Touch, Salt Lake City, UT

- Louis Hanie, Sales Representative - Hansen-All Seasons Insulation, Lindon, UT

- Steve Speirs, Owner - Steve Speirs Radiant Heat and Plumbing, Layton, UT

- Ron Call, Owner - Timberwolf Cabinets \& Fixtures, Providence, UT

\section{Suppliers}

- David Lynn, Owner - Glass Images \& Creations, Orem, UT

- John, Sales Representative -- Colonial Building Supply, Centerville, UT

- Dan Abbott, Sales Representative - St. George Winlectric, St. George, UT

- JC Marsden, Sales Representative - Riverwoods Mill, St. George, UT

- Chuck Spencer, Sales Representative - Stock Building Supply, Provo, UT

- Rich Runger, Manager - Dal-Tile, Ogden UT 


\section{APPENDIX B. DELPHI ROUND 1}

\section{Best Practices for Dealing with Price Fluctuation in Residential Construction}

Introduction:

For the purpose of this study, price fluctuation is defined as unpredictable price changes in materials, labor, and/or equipment that could potentially affect construction contracts and actual project cost.

\section{Questions}

1. Which of the following best describes your role in the construction industry?
a. Owner
b. General Contractor
c. Subcontractor
d. Supplier
e. Other (please specify):

2. How many homes did you build in the last calendar year?
a. $1-10$
b. $11-50$
c. $51-100$
d. $101-200$
e. $201-500$
f. $500+$

3. What is the average price of homes you built in the last calendar year?
a. Less than $\$ 100,000$
b. $\$ 100,000-\$ 200,000$
c. $\$ 200,000-\$ 300,000$
d. $\$ 300,000-\$ 500,000$
e. $\$ 500,000$ - $\$ 1,000,000$
f. More than $\$ 1,000,000$ 
4. What percentage of your business is done under the following types of contracts? (total should equal 100\%)

\begin{tabular}{|l|r|}
\hline Fixed Price & $\%$ \\
\hline Cost Plus & $\%$ \\
\hline Unit Price & $\%$ \\
\hline Guaranteed Maximum Price & $\%$ \\
\hline Other (please specify): & $\%$ \\
& \\
& \\
\hline & Total \\
\hline
\end{tabular}

a. Has this changed in the past few years?

5. In order of priority, what are the 3 most important methods you use to control the risk of price fluctuation?

(1)

(2)

(3) 
6. Assign the level of risk you feel is currently placed on the following parties for each type of contract, as it pertains to price fluctuation in residential construction. (total for each column should equal $100 \%)$

\begin{tabular}{|c|c|c|c|c|}
\hline & $\begin{array}{c}\text { Fixed } \\
\text { Price }\end{array}$ & $\begin{array}{l}\text { Cost } \\
\text { Plus } \\
\end{array}$ & $\begin{array}{l}\text { Unit } \\
\text { Price }\end{array}$ & GMP \\
\hline Owner/Developer & $\%$ & $\%$ & $\%$ & $\%$ \\
\hline General Contractor & $\%$ & $\%$ & $\%$ & $\%$ \\
\hline Subcontractor & $\%$ & $\%$ & $\%$ & $\%$ \\
\hline Material Suppliers & $\%$ & $\%$ & $\%$ & $\%$ \\
\hline Other (please specify) & $\%$ & $\%$ & $\%$ & $\%$ \\
\hline Total & $100 \%$ & $100 \%$ & $100 \%$ & $100 \%$ \\
\hline
\end{tabular}

7. Assign the level of risk you feel should be placed on the following parties for each type of contract, as it pertains to price fluctuation in residential construction. (total for each column should equal $100 \%)$

\begin{tabular}{|c|c|c|c|c|}
\hline & $\begin{array}{c}\text { Fixed } \\
\text { Price }\end{array}$ & $\begin{array}{l}\text { Cost } \\
\text { Plus } \\
\end{array}$ & $\begin{array}{l}\text { Unit } \\
\text { Price }\end{array}$ & GMP \\
\hline Owner/Developer & $\%$ & $\%$ & $\%$ & $\%$ \\
\hline General Contractor & $\%$ & $\%$ & $\%$ & $\%$ \\
\hline Subcontractor & $\%$ & $\%$ & $\%$ & $\%$ \\
\hline Material Suppliers & $\%$ & $\%$ & $\%$ & $\%$ \\
\hline Other (please specify) & $\%$ & $\%$ & $\%$ & $\%$ \\
\hline Total & $100 \%$ & $100 \%$ & $100 \%$ & $100 \%$ \\
\hline
\end{tabular}


8. Using a scale of 1-5, rate the various contracting methods as to their ability to equitably spread/share the risk of price fluctuation on a residential construction project? 1 being very inequitably spreads risk and 5 being very equitably spreads risk.

- Fixed Price - $\quad 1 \quad 20 \begin{array}{llll}2 & 3 & 4 & 5\end{array}$

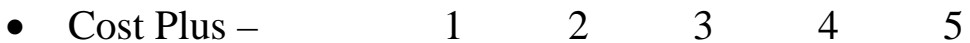

- $\quad$ Unit Price - $\quad 1 \quad 20 \begin{array}{llll}2 & 4 & 5\end{array}$

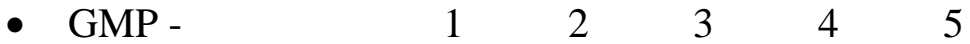

- Other (specify) - $\quad 1 \quad 2 \quad 2 \quad 3 \quad 4 \quad 4 \quad 5$

9. For each of the contracting methods, what percentage do you add to bids for potential price fluctuation in the following areas?

\begin{tabular}{|l|r|r|r|r|}
\hline & \multicolumn{1}{|c|}{$\begin{array}{l}\text { Fixed } \\
\text { Price }\end{array}$} & \multicolumn{2}{c|}{$\begin{array}{c}\text { Cost } \\
\text { Plus }\end{array}$} & \multicolumn{2}{c|}{$\begin{array}{l}\text { Unit } \\
\text { Price }\end{array}$} & \multicolumn{1}{|c|}{ GMP } \\
\hline Materials & $\%$ & $\%$ & $\%$ & $\%$ \\
\hline Labor & $\%$ & $\%$ & $\%$ & $\%$ \\
\hline Equipment & $\%$ & $\%$ & $\%$ & $\%$ \\
\hline Subcontractors & $\%$ & $\%$ & $\%$ & $\%$ \\
\hline Other (please specify) & $\%$ & $\%$ & $\%$ & $\%$ \\
\hline
\end{tabular}

10. What issues are or could be created when labor and material prices decrease rapidly? 


\section{APPENDIX C. DELPHI ROUND 2}

Introduction:

\section{Price Fluctuation Round 2 Follow-Up Questions}

When asked in Round 1 about the 3 most important methods used to control the risk of price fluctuation, respondents consisting of general contractors, subcontractors, and material suppliers from Utah's residential construction market gave a variety of answers. The most frequent responses have been categorized and used to create this follow up questionnaire. These questions are an attempt to better understand how the different parties are using these practices to control the risk associated with price fluctuation. All answers will be compiled and generalized for the final paper.

\section{Questions}

1. The 5 most frequent responses of the panel have been listed below in no particular order. According to your experience, rank the following methods in order of their effectiveness in controlling the risk of price fluctuation. (1 being the most effective of the methods, 2 being the next most effective...etc.)

- Timely Buyout - Locking in prices with contracts or purchase orders immediately following bid acceptance, in order to keep the price constant for the duration of a project.

- Contract Language - Price fluctuation language or clauses in contracts that clarify who has the risk for potential price fluctuation and/or how it will be handled.

- Inventory Management - Purchasing large quantities of materials at a certain price and storing them until needed.

- Bid Time Tables - Stipulating the amount of time a bid is good for. For example, "this bid is good for __ _ days".

- Relationships - Maintaining good relationships and regular communication regarding current pricing with subs and suppliers in order to better anticipate price fluctuation. 
2. Many of the respondents listed contract language provisions as a way to control the risk of price fluctuation. If contract language is a method you use to manage the risk of price fluctuation:

What specific contract language do you use to mitigate your risk of price fluctuation in contracts with the following parties (please answer according to your company's experience and practices):

- Owner:

- Subcontractor:

- Material Supplier:

3. Many of the respondents listed inventory management (ie stockpiling volatile materials) as an effective way to control the risk of price fluctuation. If inventory management is a method you use to manage the risk of price fluctuation:

What materials do you stockpile?

How do you determine the volume or amount of material you keep in inventory? 
4. Many of the respondents listed use of deadlines for acceptance of bid proposals as a method to control the risk of price fluctuation. A typical example would be: "this price is good for days." If you use deadlines such as this to manage the risk of price fluctuation:

How long is one of your bids good for, on average?

Do you accept time stipulations from those you contract with?

If bidding requirements prevent you from submitting a time stipulation, how do you deal with time stipulations on bids you may receive from subcontractors and/or suppliers? 